\title{
Aproximación historiográfica a la restauración patrimonial de carácter historicista en España: desde sus albores a la actualidad
}

Historiographic approach to historicist heritage restoration in Spain: from its beginnings to the present day

\section{GuILlermo L. LÓPEZ MERINO \\ Universidad de Córdoba. \\ E-mail: guille_gilome@hotmail.com \\ Orcid ID: https://orcid.org/0000-0002-9024-8549}

Resumen: El artículo tiene como objetivo la aproximación historiográfica a la historia de la restauración patrimonial desde sus orígenes hasta nuestros días, con especial énfasis en el «falso histórico», mediante la revisión bibliográfica y el análisis de distintos casos de estudio. El concepto surge en Europa en pleno siglo $X X$, pero su aparición en el terreno práctico se remonta a las primeras restauraciones románticas. La «Unidad de estilo» y su lucha contra la postura antirrestauradora marcarán el siglo XIX hasta que la nueva centuria traiga consigo el triunfo de la tendencia conservadora, matizada en lo sucesivo por diversos autores hasta llegar a un equilibrio estético-histórico. El panorama español sigue esta evolución hasta que la Dictadura Franquista impone de nuevo los valores historicistas, postura que empezará a cambiar en los albores de la democracia. A pesar de este avance teórico, la actualidad aparece dominada por criterios dispares que provocan un heterogéneo panorama restaurador.

CAUN 28 (2020): [1-32] 101-132

ISSN: 1133-1542. ISSN-e: 2387-1814

DOI: http://doi.org/10.15581/012.28.011
RECIBIDO: 7 DE NOVIEMBRE DE 2019 ACEPTADO: 7 DE DICIEMBRE DE 2019
Palabras Clave: restauración, patrimonio, «falso histórico», historicista, conservación.

Abstract: The article aims at a historiographic approach to the history of heritage restoration from its origins to the present day, with a special emphasis on the «historical fake», through literature review and analysis of different case studies. The concept emerged in Europe in the middle of the 20th century, but its appearance in the practical field dates to the first romantic restorations. «Unity of style» and its struggle against the anti-restorative posture will mark the nineteenth century until the new century brings the triumph of the conservative tendency, nuanced in the following by several authors until reaching an aesthetic-historical balance. The Spanish panorama follows this evolution until the Franco dictatorship imposes again the historicist values, a position that will begin to change at the dawn of democracy. Despite this theoretical advance, the current situation is dominated by disparate criteria that cause a heterogeneous restorative landscape.

Keywords: restoration, heritage, «false historical», historicist, conservation. 


\section{INTRODUCCIÓN}

A restauración arquitectónica, que supone una lucha continua entre la búsqueda del respeto al pasado del edificio y su correcta recuperación y proyección en la sociedad (Fernández 1997: 47), establece una serie de planteamientos éticos que han supuesto un debate continuo desde su nacimiento como disciplina, convirtiendo a esta práctica en todo un reto moral (Gallego, 2007: 17). Según Miquel Mirambell Abancó se trata de una intervención prescindible para la salvación de la materia que compone el objeto artístico, pero siempre necesaria para su correcta lectura histórico-artística (Mirambell, 2016: 4). Esta consiste esencialmente en la recuperación de un estado o cualidad perdida, deteriorada o amenazada del edificio (Fernández, 1997: 47), en repristinarlo -del latín «pristinus»: primitivo u original- (Rivera, 2008: 32); siempre, desde un proceso previo de investigación documental y arqueológica (Arrechea, 1998: 75).

La historia de la restauración patrimonial ha sido una reflexión continua acerca de lo que representa el «falso histórico» y, en consecuencia, el concepto de autenticidad, referido no sólo a la materia, sino a la esencia misma del monumento desde una valoración instrumental y un análisis histórico-crítico del objeto heredado (González, 1996: 18). El concepto fue acuñado en el siglo XX por el especialista italiano en teoría de la restauración Cesare Brandi como «falso histórico» o «falso arquitectónico». Desde esta mentalidad, un monumento reconstruido, total o parcialmente, será siempre una falsificación, por emplear elementos que no responden a la cronología primigenia. Sin embargo, si contemplamos este mismo monumento desde una perspectiva documental, será precisamente la ausencia de los elementos definidores del mismo lo que constituya una verdadera falsedad. Por tanto, la falsedad de un elemento recuperado quizás no deba juzgarse por la cronología de su materia, sino por su fidelidad a la esencia originaria (González, 1996: 21-22).

De acuerdo con ello, son dos los aspectos fundamentales que definirán una restauración historicista o falso histórico. En primer lugar, el uso de materiales o técnicas de construcción actuales sin la correcta distinción entre las partes añadidas y las originales; y en segundo lugar la reconstrucción completa o parcial del edificio con base en hipótesis no contrastadas. A partir de aquí podemos comenzar a adentrarnos en la historia de una disciplina que ha suscitado un intensísimo debate a lo largo de los tiempos, y que nos llevará a entender mejor los criterios seguidos en la actualidad.

\section{TENDENCIAS DE LA RESTAURACIÓN PATRIMONIAL EN EUROPA}

\subsection{Antecedentes}

La valoración del patrimonio personal y colectivo es una práctica que remonta casi al origen de la civilización. Ya en la prehistoria era habitual conservar vestigios de épocas anteriores, tal y como se ha constatado en numerosos yacimientos, e incluso se sabe que los hombres del Paleolítico Superior aplicaban repintes a las pinturas parietales para hacer perdurar su efecto mágico-simbólico. Este carácter cuasi divino fue continuado hacia 3000 a. C. en Mesopotamia, donde las reparaciones de templos 
antiguos eran realizadas por designio de los dioses, que se aparecían en sueños a reyes y príncipes (Amitrano, 1985: 20; González-Varas, 2000: 132; Mirambell, 2016: 8).

En el Antiguo Egipto también encontramos este tipo de reutilizaciones por orden de los faraones, como Ramsés II, que intervino en el templo de Luxor. También tenemos constancia de restauraciones de esculturas, como la realizada en uno de los brazos de una estatua colosal del propio Ramsés II bajo los auspicios del faraón Seti hacia 2000 a. C. (González-Varas, 2000: 132; Macarrón, 2013: 21; Mirambell, 2016: 10).

\subsection{Periodo clásico}

Durante esta fase el componente artístico adquiere un protagonismo sin precedentes y con él el interés por las técnicas artísticas y la conservación de las obras. En Grecia por ejemplo apostaban por la conservación preventiva, manifestada mediante la elección precisa de materiales, técnicas y pátinas para evitar la degradación de las obras pictóricas y escultóricas. En cuanto a las restauraciones, respondían al deseo de restablecer el aspecto original alterado de la obra, como los leones del templo de Zeus en Olimpia, sustituidos en época helenística al estar desgastados por el tiempo (Martínez et. al., 2008: 63; Macarrón, 2013: 23-29). La civilización romana hereda esta preocupación por el patrimonio, como podemos ver en el tratado De Architectura de Vitruvio, escrito en tiempos de Augusto. En su libro VII relata una intervención restauradora en la casa de un escribano, además de ofrecer consejos para evitar el deterioro de los objetos guardados en los edificios (Macarrón, 2013: 40; Mirambell, 2016: 13-20).

En esta época, no obstante, se tiene un nulo respeto hacia lo original, como podemos comprobar en las numerosas copias romanas de estatuas griegas, que sin embargo eran valoradas como si fueran originales. Esta mentalidad condicionó la actuación en numerosos edificios, como el Panteón de Roma. A pesar de que fuera construido en el siglo II d. C. por el emperador Adriano, una inscripción bajo el frontón indica que lo realizó Marco Agrippa. Este cónsul hizo el edificio original, pero debido a dos incendios quedó arruinado. Adriano tuvo que reedificarlo, cambiando su orientación y fisonomíaํ (Macarrón, 2013: 38; Mirambell, 2016: 22).

A pesar de este tipo de actuaciones, la valoración del patrimonio antiguo queda atestiguada por fenómenos como los spolia: reaprovechamiento de materiales constructivos o decorativos de edificios antiguos con carácter ideológico o pragmático (De Lachenal, 1995: 7; Mirri, 2009: 10-11; Peña 2010: 19). En este contexto se desarrolla la palabra monumentum ${ }^{2}$ identificada con aquellos bienes que merece la pena conservar. Contamos además con otras noticias sobre tempranas acciones de conservación, como la reparación de la estatua de Zeus de Fidias o la protección de la puerta del Mercado de Mileto, hasta que Septimio Severo establece la primera normativa para la recons-

1 El templo original de Agrippa era de planta rectangular y sin cúpula, muy distinto a la reconstrucción realizada por Adriano (Mirambell, 2016: 22).

2 Monumentum viene del verbo griego mnemo, y del latín monere: recordar (Mirri, 2009: 9). 
trucción de los bienes monumentales. Finalmente, surgen las primeras normativas de conservación preventiva, como el edicto de Valentiniano, Teodosio y Acadio de 389 d. C., que prohibía desfigurar los ornamentos externos de edificios privados mediante añadidos modernos, o estropear construcciones históricas de una ciudad (Fernández, 1997: 47; Calama y Graciani, 1998: 19; Mirambell, 2016: 23).

\subsection{Periodo medieval}

En la Edad Media de nuevo el componente místico del objeto artístico está por encima del estético, al igual que ocurriera en los orígenes del arte. Este se utiliza como herramienta para acompañar el culto a Dios, y la mayoría de las intervenciones serán modificaciones para favorecer su uso, como ocurrió en el Partenón de la Acrópolis de Atenas, transformado en el siglo $\mathrm{V}$ en iglesia mediante la construcción de un ábside (Martínez et. al., 2008: 69; Macarrón, 2013: 49; Mirambell, 2016: 25-28).

A pesar de esta actitud, también se puso empeño en conservar ciertos elementos del pasado en su estado original, como ocurrió con la columna trajana de Roma. En 1162 se promulgó un edicto que garantizaba su conservación in situ y sin añadidos, aun cuando no tenía utilidad alguna. Esta medida resulta interesante, ya que durante el Renacimiento fue coronada con una estatua de San Pedro que modificó para siempre el sentido del monumento. A pesar de este hecho insólito, en la mayoría de los casos se advierte un escaso respeto por los materiales constructivos, como deja claro el monje Hugo de Poitiers en una crónica de 1167. En ella narra el descubrimiento en la abadía de Vézelay de unas reliquias dentro de una escultura, a la que el restaurador no dudó en rascar, golpear y abrir para conseguirlas (Martínez et. al., 2008: 106; Mirambell, 2016: 25-32).

\subsection{Periodo renacentista (Siglos XV y XVI)}

Será durante este periodo cuando más se teorice acerca del concepto de monumento y las acciones susceptibles de ser llevadas a cabo sobre ellos, debido al enorme renacer de la cultura clásica, que a su vez incentiva la arqueología y el coleccionismo. El Papa Pío II firmó en 1462 una bula por la que proclamaba la conservación in situ de los monumentos de la Antigüedad de Roma, pues formaban parte del ornamento y gloria de la ciudad, y eran testimonio de virtudes antiguas. Esta manifestación es interesante pues alude ya a la doble vertiente (estética e histórica) de la arquitectura, que tan referida será en tendencias restauradoras de siglos posteriores (Macarrón, 2013: 70-78; Mirambell, 2016: 36).

Sin embargo, muchos vestigios antiguos fueron integrados en edificios de nueva planta, y lo habitual era restaurar completando o adaptando al gusto renacentista, pues no sólo se buscaba recuperar el arte pasado, sino mejorarlo. En este sentido destacó León Battista Alberti y su concepto de instauratio (restauración), mediante el que ocultó numerosas iglesias góticas con una membrana exterior e interior destinada a corregir el estilo primitivo. Este criterio, denominado por algunos de «ocultación», fue utilizado en Santa María Novella entre 1458 y 1470, si bien el objetivo principal no 
era ocultar la iglesia gótica, sino confrontar estilos y mejorar el edificio. En otras ocasiones, sin embargo, sí se optó por la continuación del estilo «primitivo»: el cimborrio de la Catedral de Milán fue finalizado en estilo gótico, con proyectos de Bramante y Francesco de Giorgio (Rivera, 1997: 106; 2008: 122-123; Mirambell, 2016: 36-49).

En este contexto de creciente valoración del patrimonio fue clave también la creación, en noviembre de 1534, de la Comisión Central para la Conservación de Monumentos Antiguos de Roma por parte del Papa Paulo III, aunque ya antes León X había dado muestras de un interés notable en estas cuestiones, nombrando al pintor Rafael Sanzio director de las Excavaciones Romanas (Martínez et. al., 2008: 221; Fernández, 1997: 48; Rivera, 2008: 41; Mirambell, 2016: 35).

Los escultores renacentistas de primera fila también restauraban asiduamente obras antiguas fragmentadas. Lo hacían completando lo que les faltaba, pero siempre procurando que lo añadido pareciera antiguo, creando así un hibrido que rayaba la falsificación histórico-artística. Célebre es el caso de la loba capitolina ${ }^{3}$, escultura etrusca de bronce que fue acompañada en el Quattrocento por sendas estatuillas de los gemelos Rómulo y Remo realizadas por Antonio de Pollaiuolo. De esta manera se creó un falso documento histórico-artístico que dio soporte a la leyenda de la fundación de Roma (Martínez et. al., 2008: 104; Mirambell, 2016: 39-50).

\subsection{Periodo barroco (Siglo XVII y primera mitad del XVIII)}

Este periodo destaca por el acusado academicismo, que suscita un interesante debate en el mundo del arte y la restauración. La primera academia es fundada en 1648 por el rey francés Luis XIV, quien apadrinó la manera de restaurar del periodo anterior. Este hecho podemos comprobarlo en la intervención acometida en la Venus de Arlés, escultura clásica hallada en 1651 y regalada a dicho rey. Como ocurrió en otras obras, había perdido los brazos, que fueron reintegrados por el escultor francés François Girardon en 1684. Sin embargo, lo hizo colocándolos en una posición completamente inventada y añadiendo una manzana en una de las manos para cristianizar la imagen. Este hecho comporta un problema para la lectura de la obra, al tiempo que eliminar hoy los añadidos supondría renunciar a una parte de la historia de la escultura (Mirambell, 2016: 57-58).

A pesar de los excesos, el gran logro de este periodo fue la aparición de un restaurador más profesional, que iría sustituyendo al artista, más creativo. Destacaron al respecto Francia e Italia, la primera con una actitud más restauradora y la segunda más proclive a la conservación, dicotomía continuada con el paso de los siglos (Mirambell, 2016: 60).

\footnotetext{
Algunos estudios consideran que es medieval y no etrusca, si bien nunca anterior al siglo $\mathrm{X} \mathrm{d}$. C. (Mirambell, 2016: 49).
} 
También en el Barroco se produce un cambio de paradigma, pues a diferencia del Renacimiento ya no se perseguía mejorar la obra deteriorada, sino imitar el estilo de los antiguos maestros, aunque para ello se hicieran restauraciones estilísticas. Todo ello suscita un profundo debate que permite plantear por primera vez el concepto de mínima intervención. Será el pintor Luigi Crespi en 1756 quien muestre públicamente su desacuerdo ante la reintegración de objetos arqueológicos, alentando además a no limpiar las pátinas naturales, tal y como haría John Ruskin un siglo después. También alude por primera vez al criterio de reversibilidad, pues sólo consideraba adecuada la reintegración si lo añadido era reversible y no deformaba el original (Mirambell, 2016: 72-73).

\subsection{Periodo neoclásico (Segunda mitad del siglo XVIII y principios del XIX)}

Será durante el siglo XVIII cuando verdaderamente comience a plantearse el patrimonio bajo una conciencia crítica, gracias sobre todo al descubrimiento de Pompeya, Herculano y Paestum, que aceleró la nueva manera de entender las obras de arte del pasado y su restauración mediante criterios arqueológicos. Precisamente en la difusión del Neoclasicismo tuvieron mucho que ver estos hallazgos, unidos también a las aportaciones de Johannes Joachim Winckelmann, quien ideó un nuevo método de estudio de la historia del arte basado en los estilos, distinguiendo además épocas y periodos dentro de los mismos. Este hecho resultó clave igualmente en el campo de la restauración arquitectónica, pues permitió una mejor identificación de los monumentos clasificándolos por cronologías (Rivera, 1997: 109-110; 2008: 124; Macarrón, 2013: 155; Mirambell, 2016: 77-78).

La admiración de Winckelmann por el arte clásico era tal que consideraba a los artistas antiguos superiores a sus contemporáneos, poniendo en duda muchas de las restauraciones de su época. Se mostró partidario de la reintegración de esculturas, pero no como en el Renacimiento, sino imitando el estilo del maestro antiguo. A pesar de la evidente falsificación, su visión estaba basada en una sólida investigación documental de la obra, con las que sentó las bases de la restauración estilística. Y es que su preocupación por la restauración fue tal que llegó a asociarse con el escultor restaurador Bartolomeo Cavaceppi, creando el primer equipo interdisciplinar de la historia para la restauración de esculturas antiguas (Martínez et. al., 2008: 209-210; Macarrón, 2013: 192-193; Mirambell, 2016: 79-80).

Sin embargo, esta no fue la única tendencia de la época. El arquitecto Giovanni Battista Piranesi invitaba a la conservación de las ruinas arquitectónicas y no a su restauración, mostrándose muy interesado en documentar las secuelas del paso del tiempo en los monumentos, tal y como manifestaría tiempo después John Ruskin. De hecho, la dicotomía ideológica Cavaceppi-Piranesi se adelantó casi un siglo al debate teórico que durante años protagonizarían Viollet le-Duc y el propio John Ruskin (Mirambell, 2016: 81). 
La tendencia ruinista de Piranesi resultó fundamental para la formulación en Italia de la primera teoría restauradora de la historia: el denominado «Restauro Archeologico», que generó una manera de enfrentarse a la restauración muy respetuosa para la época, con el fin de completar o consolidar los edificios, pero diferenciando sutilmente las partes nuevas de las originales. Una de las intervenciones más representativas de esta escuela fue la realizada en el Coliseo romano bajo el Papado de Pío VII. Entre 1806 y 1807 Raffaele Stern acometió la restauración de la fachada oriental mediante un contrafuerte de ladrillo que soportó la fachada, a la vez que «congelaba» los bloques de travertino caídos durante el terremoto del año 442, dejándolos suspendidos entre los ladrillos del contrafuerte (Rivera, 1997: 113; 2008: 128; Macarrón, 2013: 224 Mirambell, 2016: 81-83).

Cuatro años después Giuseppe Valadier prosiguió con la restauración de la fachada bajo los mismos criterios arqueológicos, pero su contrafuerte estaba compuesto por arcos de ladrillo que reconstruían los originales. La diferencia entre ambas intervenciones es que la de Stern puede encuadrarse dentro de una conservación pasiva, que plantea el edificio como una arquitectura ya muerta, mientras que Valadier intenta ir más allá tratándolo como un espacio aún funcional (Figura1). A pesar de estos notables avances, esta forma de pensar no tendría continuidad, pues durante la segunda mitad del siglo XIX Italia derivaría hacia las teorías restauradoras francesas (Rivera, 1997: 114-115; 2008: 129-131; Martínez et. al., 2008: 223; Mirambell, 2016: 84-85).

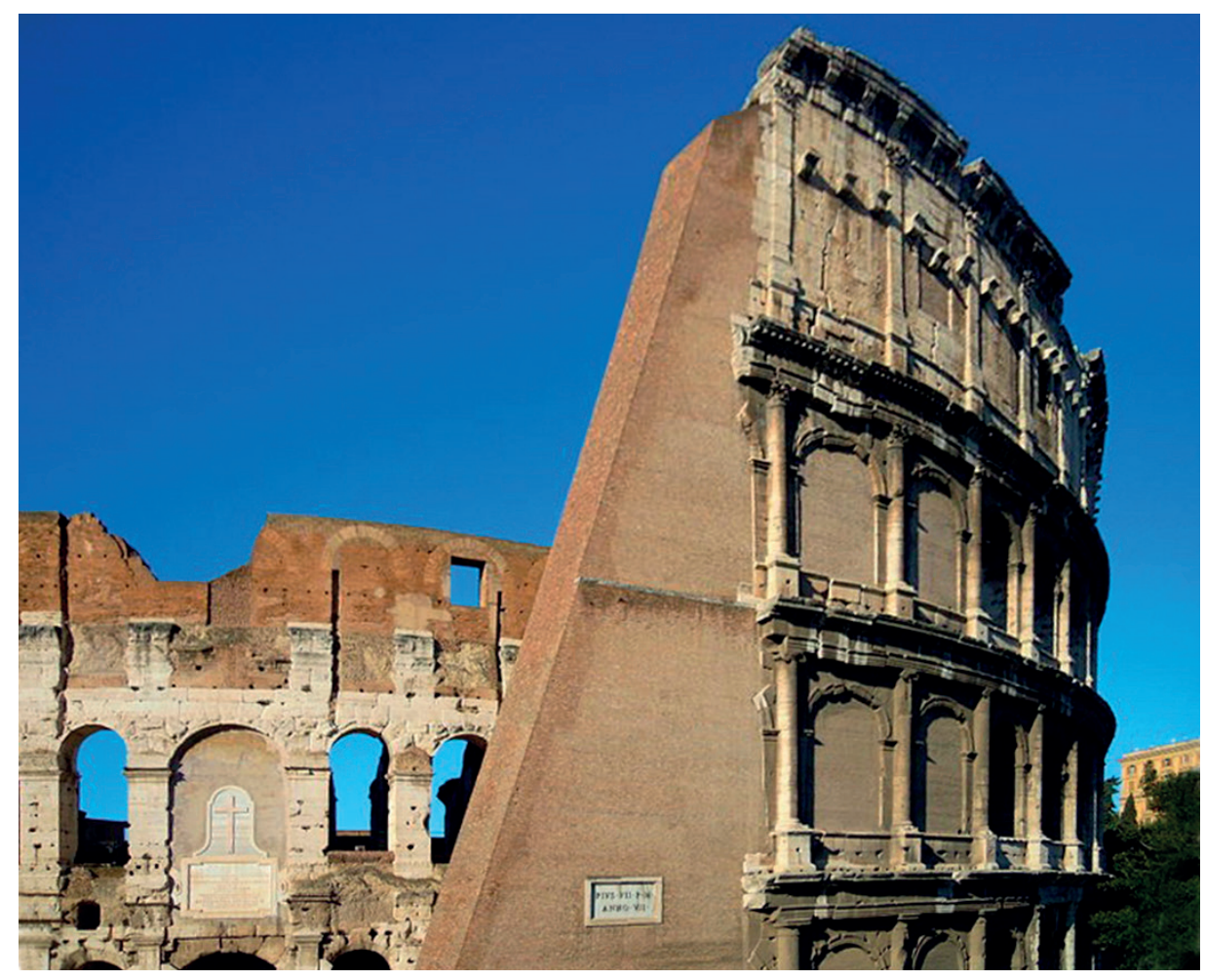

Figura 1

Roma. Coliseo. Restauración de Raffaello Stern

Fuente: https://es.wikipedia.org/wiki/Archivo:Roma_coliseo.JPG 


\subsection{Periodo romántico-estilístico (Siglo XIX)}

Será ya bien entrado el siglo XIX cuando comenzará la verdadera historia de la práctica restauradora (Bellini, 1998: 9-10). Con sólo algunas excepciones, lo normal hasta este periodo era restituir los elementos arquitectónicos de los edificios en el estilo imperante de cada momento, desfigurando así su aspecto original. Paradójicamente, eso ayudó a crear una especial sensibilización por la historia, y generó dos claras actitudes: la de historiadores y arqueólogos, por un lado, y la de los arquitectos por otro. Los primeros abogaban por el respeto absoluto hacia el monumento como documento histórico, y los segundos enfatizaban el lenguaje estilístico del mismo (Ordieres, 1995: 115; Capitel, 1998: 34-36).

En líneas generales, la improvisación y el desconocimiento de las técnicas constructivas del pasado marcarán inicialmente las actuaciones de este periodo, que buscan sobre todo la recuperación de la personalidad perdida del edificio. Su estado original y brillantez primitiva se convirtieron en un medio evocador del pasado, en particular del arte de la Edad Media, que tan apreciado era por los románticos (Ordieres, 1995: 116-117, Mirambell, 2016: 96).

El concepto que definirá esta etapa es el de «Unidad de Estilo», si bien podemos diferenciar dos claras tendencias que marcarán el debate durante el siglo XIX: la violletiana-racionalista (restauración estilística), y la histórico-arqueologista (restauración romántica). La primera tiene como punto de partida las reflexiones estilísticas que surgieron gracias a los estudios tipológicos de Ludovic Vitet ${ }^{4}$ Este corpus teórico fue luego aplicado a los monumentos mediante el análisis comparado que ya se había utilizado en otras materias como la Botánica o la Filología para demostrar la existencia de leyes internas (Ordieres, 1995: 119; Bellini 1998: 15-16).

El máximo representante de esta tendencia fue Eugène Viollet le-Duc ${ }^{5}$ (Figura 2), para el que forma y estructura estaban perfectamente emparentadas, ya que cada elemento arquitectónico era consecuencia de una necesidad estructural que permitía deducir las ausencias a partir de un profundo conocimiento del estilo gótico. Esta teoría estaba basada en la correlación de los órganos del naturalista George Cuvier ${ }^{6}$, en un alarde de la actitud científica con la que Viollet le-Duc acometía sus restauraciones (Ordieres, 1995: 119-120, Martínez, 1999: 19; Mirambell, 2016: 96-99). El concepto que él defendía de restauración quedará expresado en 1868 en la célebre definición de su Diccionario razonado de arquitectura, que marcará la manera de actuar de su tiempo:

${ }_{4}$ Primer Inspector General de Monumentos de Francia, defensor de alcanzar en el monumento la unidad coincidente con su estado primitivo, idea que influirá decisivamente en Viollet-le-Duc (Rivera, 2008: 135; Mirambell, 2016: 98).

5 Si bien Viollet le-Duc es la figura más destacada de la restauración estilística, su formulación teórica parte de Prosper Merimée (Inspector General de Monumentos Históricos de Francia) quien afirmaba que era preciso olvidar el tiempo en que se vive para convertirse en contemporáneo de lo que se restaura (Macarrón, 2013: 214; Mirambell, 2016: 98).

${ }^{6}$ Según su teoría, unos caracteres siempre van vinculados a otros y excluyen a unos terceros, lo cual permite reconstruir especies a partir de fragmentos óseos (Mirambell, 2016: 99). 
«Restaurar no es mantener un edificio, conservarlo o repararlo sino restablecerlo en un estado completo que puede no haber existido jamás en un momento dado». Sin embargo, cuando los restos de un monumento resultaban insuficientes para recomponerlo por el sistema de correlación de formas, recurría al método analógico, es decir, buscaba monumentos de la misma época y estilo y los copiaba sin tener en cuenta que pudiera resultar una falsificación (Navascués, 1987: 296; García, 1998: 259; Martínez et. al., 2008: 231; Mirambell, 2016: 98-100).

La otra gran tendencia de la época, la llamada «Antirrestauradora»o «romántica», estará encabezada por la figura de John Ruskin (Figura 3), quien, en su obra fundamental de 1849 Las Siete Lámparas de la Arquitectura, hará una defensa del concepto de pátina de los edificios como belleza añadida accidental. Es en el capítulo titulado la «Lámpara del Recuerdo» en el que desarrolla perfectamente sus postulados acerca de restauración y conservación (Navascués, 1987: 298; Gallego, 1992: 29; Martínez et. al., 2008: 233): «(...) la restauración puede llegar a ser una necesidad. De acuerdo. (. ..) rehacedlos de lastre o mortero a vuestro gusto, mas, hacedlo honradamente, no los reemplacéis por una mentira. (...) tened cuidado de vuestros monumentos y no tendréis luego la necesidad de repararlos. (...)» (Ruskin, 1956: 257-258; Ordieres, 1995: 123-124; Rivera, 2008: 147-148; Mirambell, 2016: 121-122).

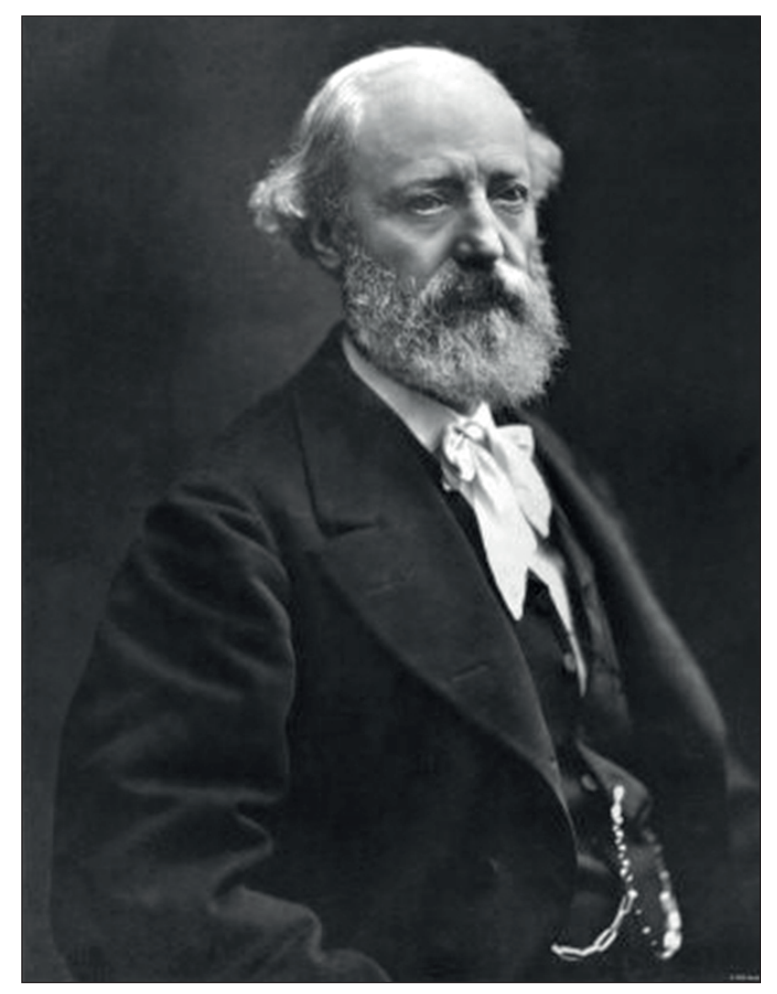

Figura 2

Eugène Viollet le-Duc

Fuente: https:/ / upload.wikimedia.org/ wikipedia/commons/4/4d/Eugene_viollet_ le_duc.jpg

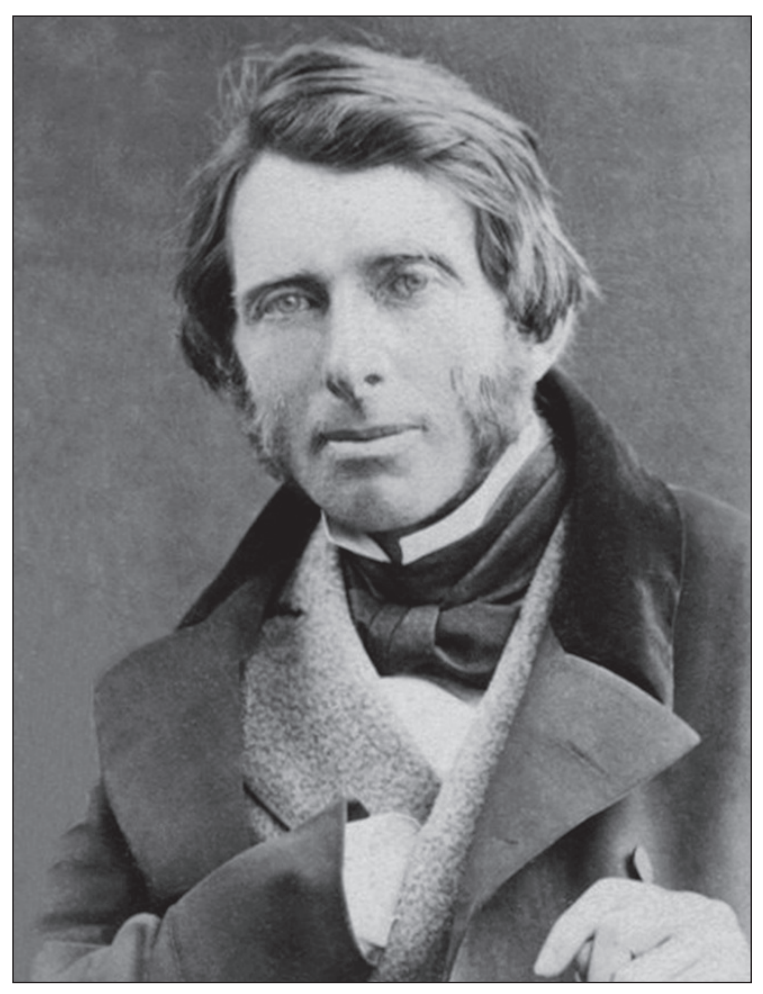

Figura 3

John Ruskin

Fuente: https:/ / es.wikipedia.org/wiki/ John_Ruskin\#/media/File:John_Ruskin_ 1863.jpg 
Lo que verdaderamente movía a Ruskin era una ética basada en el culto a la belleza y la verdad de la Historia, con una obsesiva llamada a la autenticidad como única legitimadora del placer estético (Ordieres, 1995: 126). Y es que para Ruskin no se debían tocar los monumentos del pasado, pues toda restauración significaba la destrucción más completa de un edificio, ya que violentaba la esencia de la ruina y llevaba al engaño y la falsificación histórica. Además, entendía los monumentos como parte de la naturaleza, valorando el paso del tiempo y todas las modificaciones realizadas sobre ellos. Ruskin, cuyo pensamiento era sin duda producto de las teorías ruinistas de Giovanni Battista Piranesi, consideraba, por tanto, al contrario que Viollet le-Duc, que se podía conservar sin necesidad de restaurar. Con todo, a pesar de su incesante crítica a la teoría violletiana, Ruskin dejó constancia de su admiración por el arquitecto francés, al que consideraba el guía más atento e informado sobre el arte del 800 al 1200 (Navascués, 1987: 298; Martínez, 1999: 20; González-Varas, 2000: 204; Mirambell, 2016: 122-125).

En medio de esta vorágine de tendencias contradictorias, surgen en Italia a finales del siglo XIX dos teorías restauradoras catalogadas como positivistas, pues se acercan cada vez más a la actitud científica. La primera es el llamado «Restauro Storico», de la mano de Luca Betrami, cuya máxima aportación fue la de potenciar la fase de documentación para restaurar solo a partir de datos ciertos e irrefutables. Sin embargo, en la práctica este método fue un desastre, ya que todavía no existía la suficiente capacidad crítica para entender las fuentes, surgiendo errores y excesos constructivos. Por otra parte, ante la ausencia de evidencias documentales Beltrami no dudó en aplicar el método analógico, tal y como hacía Viollet le-Duc. Esta técnica fue utilizada en la reconstrucción de la torre de entrada al castillo de los Sforza, inspirándose para ello en un diseño de Da Vinci y en otros castillos italianos (Rivera, 1995: 155; 1997: 137; Martínez, 1999: 32-33; Martínez et. al., 2008: 244; Mirambell, 2016: 129-130).

Pero sin duda es Camilo Boito (Figura 4) quien articula la gran teoría restauradora de Italia, el «Restauro Moderno» o «restauración científica», que intentará conciliar las dos grandes tesis del siglo XIX mediante la formulación de un método que no renunciaba a la restauración, como hacía Ruskin, pero que tampoco perseguía la reintegración estilística de Viollet le-Duc. Esto fue posible gracias al desarrollo del concepto de conservación, a la vez que aceptaba la necesidad de añadir en ocasiones partes nuevas, aunque diferenciándolas en cuanto a técnica y materiales. Boito era consciente además de la importancia de reunir toda la documentación posible de las etapas constructivas del edificio, para conocer bien su evolución, desarrollo estructural y estilos, en vez de tratar de descubrir qué aspecto tuvo en un periodo concreto (Ordieres, 1995: 138; Martínez, 1999: 33; Rivera, 2008: 158-160; Martínez et. al., 2008: 241; Mirambell, 2016: 133-134).

Lo realmente interesante de esta teoría es que fue la primera formulada en términos relativos, pues admitía distintas maneras de actuar según cada caso. De hecho, establecía tres categorías o niveles de restauración: «arqueológica», dirigida a los 
edificios de la antigüedad clásica y que suponía una mínima intervención; «pictórica», aplicada a los edificios medievales y que pretendía conservar los valores pintorescos tan apreciados durante el Romanticismo; y «arquitectónica», llevada a cabo en edificios de época renacentista y posteriores para devolverles su uso y unidad compositiva (Mirambell, 2016; 134-135)

A pesar de su modernidad el método

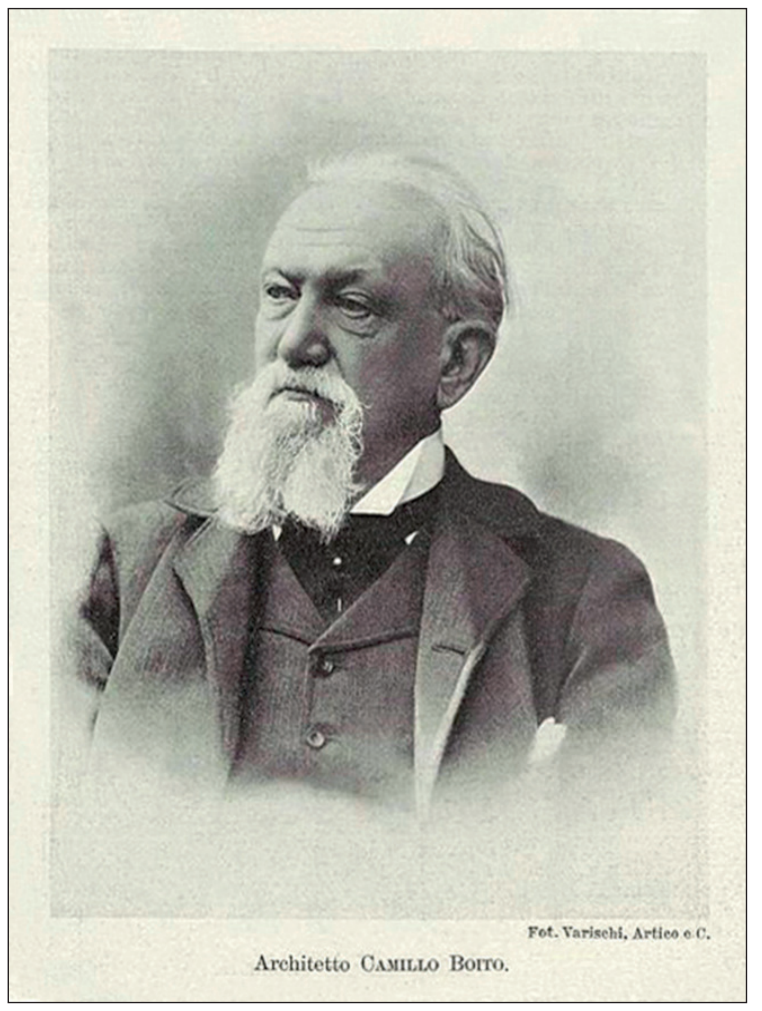

Figura 4

Camilo Boito

Fuente: https:/ / commons.wikimedia.org/ wiki/File:Arch._Camillo_Boito_(1836-1914).jpg de Boito provocaba un rechazo en el espectador no especializado, pues dotaba a los edificios de un aspecto de provisionalidad producto de los elementos de nueva factura incorporados. Es por ello que sus doctrinas, aun cuando de enorme importancia, serán reinterpretadas y ampliadas hasta llegar a la Carta del Restauro de 1932, considerada como el verdadero triunfo de las directrices pro-conservadoras frente a las líneas pro-restauradoras decimonónicas (Ordieres, 1995: 138-139).

\subsection{Periodo científico (Primera mitad del siglo XX)}

Si bien desarrolló la mayor parte de su trabajo en el siglo anterior, el historiador del arte Alois Riegl merece una especial atención por sus aportaciones e influencia a las teorías restauradoras del siglo XX. En uno de sus escritos más conocidos, Culto moderno a los monumentos (1903), sistematizó una serie de valores que debían determinar la manera de intervenir en ellos, buscando conciliar los históricos y los de antigüedad. Los primeros hacían alusión al carácter representativo de una etapa determinada de la historia, siendo de mayor valía cuanto menor hubiera sido el desgaste sufrido en el edificio, lo que favorecía su restauración. En cambio, el valor de antigüedad era mayor cuanto más hubiera actuado la erosión en la forma y color del monumento, ya que así se expresaba su ciclo vital, lo que daba pie a rechazar por completo cualquier tipo de intervención que no fuera meramente conservadora. Ambos constituían lo que Riegl denominaba valores rememorativos, a los cuales era necesario añadir los de contemporaneidad: el valor instrumental o de uso, en el que prevalecía el sentido utilitario del monumento, permitiendo también actuar sobre él; y el valor artístico, que durante el siglo XIX fue el que animó la rehabilitación de gran número de monumentos (Ordieres, 1995: 147-149; Rivera, 2008: 108; Martínez et. al., 2008: 277-279; Mirambell, 2016: 153-156). 
Lo realmente relevante de esta serie de valores es que un monumento puede tener varios a la vez, incluso llegando a entrar en contradicción. El predominio de un valor sobre otro determinará que se acabe conservando, restaurando o incluso no interviniendo, pues cada monumento es distinto (Mirambell, 2016: 160).

La nueva etapa restauradora tendrá muy en cuenta estas consideraciones, al igual que los postulados establecidos por Boito en el periodo anterior. En este contexto surge la figura de Gustavo Giovannoni y su «Restauro Scientifico», uno de los redactores más importantes de la Carta de Atenas de 1931 y el responsable y promotor de su versión italiana de 1932, la Carta del Restauro. Entre sus más interesantes aportaciones están la de ampliar el concepto de monumento a cualquier construcción del pasado, incluso modesta, además de proteger el entorno y defender del principio de mínima intervención, apostando por el mantenimiento, consolidación y respeto de toda etapa histórica del edificio (Rivera, 2008: 163-167, Mirambell, 2016: 160).

Todas las aportaciones comentadas hasta aquí fraguan en la comentada Carta de Atenas, suscrita en 1931 tras la enorme destrucción de patrimonio de la Primera Guerra Mundial. Su importancia radica en que marcará las grandes pautas de actuación conservadora durante gran parte del siglo XX, entre las que destacan por ejemplo el abandono de las reconstrucciones completas en favor de la conservación regular y permanente, y la consigna de mantener el uso de los monumentos cuando fuera posible, siempre respetando su carácter histórico o artístico. Por último, se manifestaba claramente a favor de la anastilosis en las ruinas y la utilización de materiales nuevos en éstas (sobre todo hormigón), siempre reconocibles como tales y tras la realización de rigurosos estudios científicos (Carta de Atenas, 1931; Ordieres, 1995: 154-155; Martínez, 1999: 328; Mirambell, 2016: 156).

\subsection{Periodo crítico (segunda mitad del siglo XX hasta la actualidad)}

Surge como réplica a los criterios de Boito, de Giovannoni y de la propia Carta de Atenas, cuyos postulados regían las intervenciones de urgencia en numerosos edificios en peligro de destrucción (Rivera, 2008: 178). El nuevo pensamiento fue resultado de las reflexiones de especialistas como Roberto Pane, que desarrolló la teoría del Restauro Critico, con la que rechazaba el método científico y buscaba reintegrar la forma del monumento. Pero, sin duda, su máximo representante fue Cesare Brandi (Figura 5), cuya mayor contribución fue la de criticar el exceso de valoración del aspecto histórico de los edificios, defendiendo también el reconocimiento de su calidad artística mediante un juicio crítico de los elementos estéticos que conformaban su imagen (Rivera, 1997: 148; 2008: 196; Martínez et. al., 2008: 297; Mirambell, 2016: 164).

Si bien este criterio recuerda a los postulados violletianos, la restauración crítica no es tan permisiva con las reconstrucciones, y persigue, más que la unidad estilística, la liberación de la verdadera forma del edificio, eliminando los añadidos que desnaturalizan su valor estético. En este sentido distingue entre los añadidos, incorporaciones que dan muestra de la actividad humana en distintas épocas y las reconstrucciones, 


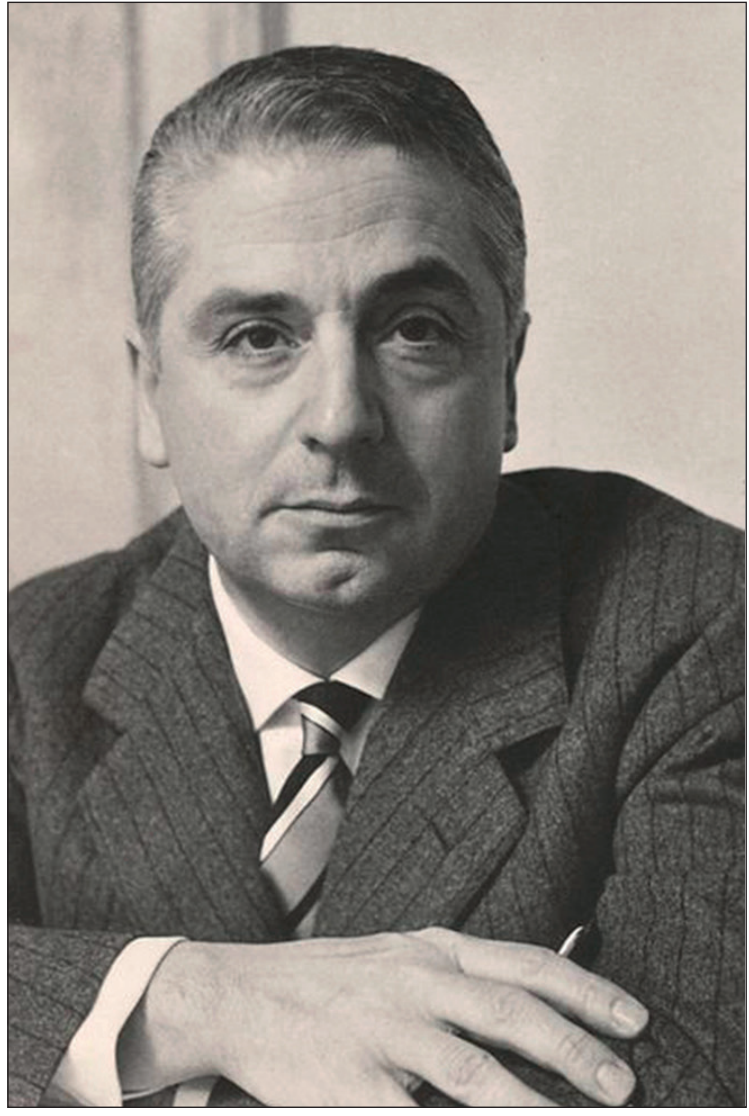

Figura 5

Cesare Brandi

Fuente: https://it.wikipedia.org/wiki/ File:Cesare_Brandi.jpg

que son un intento de conformar de nuevo la obra, cayendo en ocasiones en la falsificación histórica. Y es que Brandi se mostró siempre muy crítico con la copia, siendo incluso contrario a la sustitución de piezas originales por réplicas como medida de conservación (Rivera, 1997: 148-149; 2008: 196; Mirambell, 2016: 164-170).

En 1964 tiene lugar en Venecia una nueva reunión internacional de la que emana la Carta homónima. En ella se reafirma la consideración de los monumentos como patrimonio de la humanidad y se defiende el carácter internacional de los principios encaminados a su conservación y restauración, pero dejando siempre libertad a cada país para actuar conforme a su propia cultura y tradiciones. La Carta de Venecia incentiva el uso de las técnicas tradicionales sin rechazar las más actuales cuando las primeras no fueran suficientes para el mantenimiento del monumento. Insiste además en el carácter excepcional de toda restauración, que debe ser reversible y detenerse allí donde comienzan las hipótesis, y enfatiza el respeto por todas las fases históricas y la necesidad de un estudio arqueológico e histórico previo (Carta de Venecia, 1964; Martínez, 1999: 339-340; Pardo, 2006: 66-67; Mirambell, 2016: 158-159).

Se sentaron así las bases de la posterior Carta de Cracovia (2000), en la que se define el concepto de autenticidad como la suma de características sustanciales históricamente determinadas: desde el original hasta el estado actual, incluidas las diversas transformaciones ocurridas en el tiempo. En las tareas de conservación de monumentos y ciudades históricas la Carta de Cracovia admite los añadidos de obra nueva para garantizar la reparación y el mantenimiento, pero siempre opuesta a la reconstrucción de partes completas del edificio en su estilo original. Únicamente podrán ser repuestos de forma completa elementos muy limitados y bien documentados, y siempre bajo el criterio de reversibilidad de las actuaciones acometidas (Carta de Cracovia, 2000; Pardo, 2006: 78-79; Martínez et. al., 2008: 338). Por otro lado, hay que tener en cuenta que el verdadero éxito de una restauración no estará sólo en la adopción de los criterios más respetuosos con el monumento, sino también en la adecuación de este para su uso futuro, idea que supone ir un paso más allá en la ética intervencionista (Pardo, 2006: 77). 


\section{HISTORIA DE LA RESTAURACIÓN ARQUITECTÓNICA EN ESPAÑA}

\subsection{Antecedentes}

El término restauración surge en el castellano de la Edad Media, pero lo hace vinculado a una primera o segunda construcción edilicia para recordar y dignificar otra ya perdida. Esta medida no conllevaba la recuperación del estado primitivo del edificio antiguo, sino únicamente su función. Posteriormente encontramos algunas actuaciones con un carácter más bien reparador, como la llevada a cabo en el Acueducto de Segovia en 1481 por la Reina Isabel de Castilla (Rivera, 2008: 32-36).

Durante el Renacimiento y el Barroco se buscará la adecuación de los edificios antiguos a las nuevas expresiones artísticas, realizando reformas que transformaban su imagen (Rivera, 2008: 52). Esta tendencia continuará con el Neoclasicismo, hasta que a partir de 1750 se desarrolla en España una nueva forma de entender y valorar la historia y la arquitectura gracias sobre todo al pensamiento ilustrado (Rivera, 2008: 69). En 1752, bajo el reinado de Fernando VI, se funda la Real Academia de San Fernando, con la arquitectura como una de sus materias fundamentales. Esto le llevó a incrementar el interés por las antigüedades, llegando incluso a enviar al joven arquitecto y miembro de la Academia, Juan de Villanueva, a estudiar las arquitecturas nazaríes de Granada, con ánimo de recopilar datos sobre el patrimonio arquitectónico español. Este deseo coincide con el nuevo interés surgido en Europa gracias al descubrimiento de las ciudades de Pompeya y Herculano (Martínez, 1999: 22).

\subsection{Las primeras restauraciones nacionales}

Los verdaderos inicios de la restauración arquitectónica en España hay que buscarlos en el siglo XIX (Ordieres, 1995: 115). En 1803, Carlos IV firma la Real Cédula de 6 de julio sobre el modo de conservar y recoger los monumentos antiguos. Sin embargo, la Guerra de la Independencia (1808-1814) paraliza esta y otras medidas de protección (Rivera, 2008: 109-110).

Las primeras restauraciones se harán todavía a instancias de la Corona, antes de que se institucionalizase la protección estatal, siendo la Alhambra de Granada y el Alcázar de Sevilla los dos grandes monumentos intervenidos en esta etapa, pertenecientes ambos al Patrimonio Real. Ello demuestra no tanto el interés real por evidenciar la originalidad arquitectónica española cuanto una clara influencia de la monarquía francesa de 1830, mucho más avanzada en el ámbito de la restauración arquitectónica. Sin embargo, el interés se centró en el arte árabe y no en el gótico, como ocurriría en Francia (Ordieres, 1995: 115-116).

El objetivo de la restauración arquitectónica de este primer periodo era el de devolver al edificio su fisonomía primigenia, es decir su espíritu o carácter, como en el caso de la Catedral de Mallorca: el arquitecto Juan Bautista Peyronnet restaura y termina su fachada en 1849 basándose en modelos góticos italianos, a pesar de la evidente relación del edificio con el gótico catalán. La otra gran empresa restauradora 
de este periodo va a ser la Catedral de León. Desde 1859 hasta 1868, el arquitecto Matías Laviña Blasco propondrá solucionar los problemas estructurales del monumento desmontando grandes zonas del templo. De igual modo, rechazó todos los elementos arquitectónicos que no fuesen góticos, a fin de devolver la Catedral a su estado original, aun admitiendo que este no podía conocerse con claridad debido a las numerosas reformas de las que fue objeto a partir del siglo XVII (Navascués, 1987: 299; Mora, 1999: 55-58; Ordieres, 2008: 116-118).

\subsection{La llegada de nuevas corrientes restauradoras}

A partir de 1865 comenzarían a llegar a España las nuevas corrientes que desde Francia se habían desarrollado a partir de los años treinta, con un enorme énfasis en la noción de estilo de Viollet-le-Duc (Ordieres, 2008: 119). De hecho, tal fue el éxito del arquitecto francés, que en 1868 fue nombrado Académico Honorario de la Real Academia de San Fernando de Madrid (Mirambell, 2016: 109). Los arquitectos españoles se formarían en la lectura de revistas mayoritariamente francesas, con las que fueron conformando sus propios criterios. A partir de los años setenta poseerán ya una importante carga teórica, con la que comenzaron a desarrollar sus propios escritos y proyectos (Ordieres, 2008: 126-127).

Algunos de los proyectos estilísticos más destacados de este periodo fueron la terminación de la fachada de la Catedral de Barcelona bajo proyecto de José Mestres, que por inducción racionalista rehízo completamente las partes no existentes; o la intervención en las Casas Consistoriales de Sevilla, donde el arquitecto Demetrio de los Ríos realizó una nueva fachada hacia la Plaza de San Francisco imitando la impronta renacentista del monumento y destruyendo la antigua fachada de Hernán Ruiz II (Navascués, 1987: 308; Ordieres, 2008: 127; Méndez, 2012: 70; Parejo, 2015).

Aun cuando la aceptación de la teoría violletana fue máxima, en España se enfatizó mucho más la veracidad del estilo que la de materiales y técnicas constructivas, lo que ha llevado a algunos a llamarla «restauración espléndida». Una de sus características definitorias fue que su teoría se desarrolló a pie de obra, mientras se ejecutaban los trabajos de restauración e iban surgiendo problemas. Precisamente, es la ya comentada intervención en la Catedral de León el mejor ejemplo de la restauración estilística española, gracias a la participación de grandes maestros como Matías Laviña, Juan de Madrazo o Demetrio de los Ríos (Mora, 1999: 60; Ordieres, 1995: 115; Mirambell, 2016: 112-113).

Pero, sin duda, el máximo defensor de la teoría violletiana fue Vicente Lampérez y Romea (Figura 6), quien también comenzó su experiencia laboral como auxiliar en las obras de la Catedral leonesa (Gallego, 1998: 117-119; Ordieres, 2008: 140-141). Lampérez desplegó desde el primer momento una campaña combativa contra las teorías más conservadoras venidas desde Inglaterra, defendiendo la restauración como vía para no perder nuestros monumentos. Para él, esta acción consistía en volver a construir las partes arruinadas, o a punto de caer en la ruina, en el mismo estilo arquitectónico original (Ordieres, 1995: 142; Macarrón, 2013: 220). 
Para argumentar esta afirmación recurría a la idea de que los monumentos eran «tipos expresivos» de cada época histórica, y su estilo una manifestación directa de la cultura o pueblo que los habían construido (Gallego, 1998: 120). Por otro lado, para huir de la falsificación Lampérez proponía que las partes reconstruidas fueran copia de aquéllas que habían perdurado, utilizando en la medida de lo posible los materiales originales. De esta manera evitaba caer en la subjetividad, a la vez que intentaba unificar las posturas del bando conservador con las pro-restauradoras (Ordieres, 1995: 143-144).

Célebre es también la figura de Benigno de la Vega-Inclán y Flaquer, Marqués de la Vega-Inclán. Pero su relevancia no viene por estar a favor de la tendencia estilística imperante, sino todo lo contrario. Sus consideraciones acerca de la restauración arquitectónica las puso en práctica en la intervención que realizó en 1914 en el Patio del Yeso del Alcázar de Sevilla. Siguiendo un criterio eminentemente anti-restaurador, sacó a

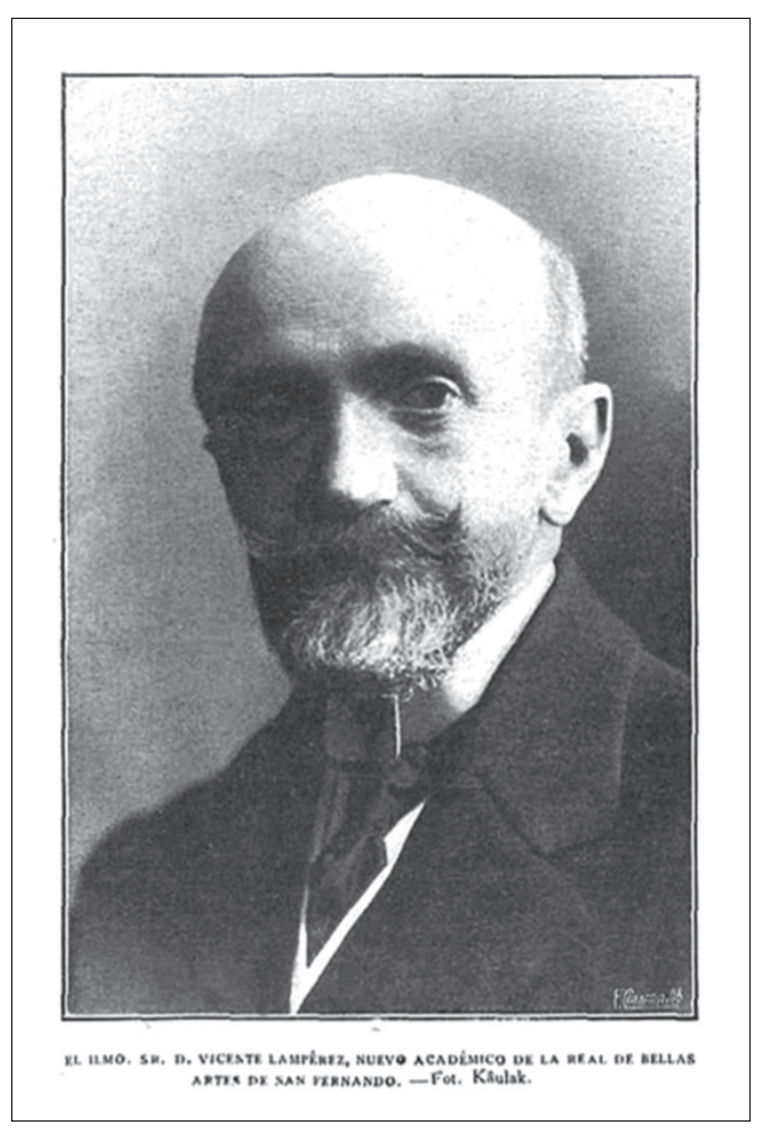

Figura 6

Vicente Lampérez y Romea

Fuente: https:/ /es.wikipedia.org/wiki/ Archivo:Vicente_Lamp\%C3\%A9rez,_de_ Kaulak.jpg la luz partes del Palacio desaparecidas, utilizando tabiques de ladrillos en los arcos descubiertos allá donde la decoración de los paños de sebka faltaba, con una perfecta distinción entre lo antiguo y lo nuevo (Navascués, 1987: 321; Mora, 1999: 54: Ordieres, 1995: 146).

\subsection{El desarrollo de las teorías conservacionistas}

El siglo XX marcará sin lugar a duda el viraje hacia las teorías conservacionistas, teniendo como punto de inflexión el Real Decreto del 23 de abril de 1915. El Ministerio de Instrucción Pública y Bellas Artes quiso con esta norma excluir toda obra de restauración de los futuros proyectos que se iban a realizar en la Alhambra. En este ambiente cobra especial importancia la figura del arquitecto Leopoldo Torres Balbás (Figura 7), que en la revista Arquitectura manifestó su crítica a la restauración violletiana (Muñoz, 2005: 26; Ordieres, 1995: 150; Martínez et. al., 2008: 292; Mirambell, 2016: 120).

La descalificación que a estas alturas se hacía en España de estas teorías era ya absoluta, después de los intentos de algunos arquitectos de matizar sus dogmas, 


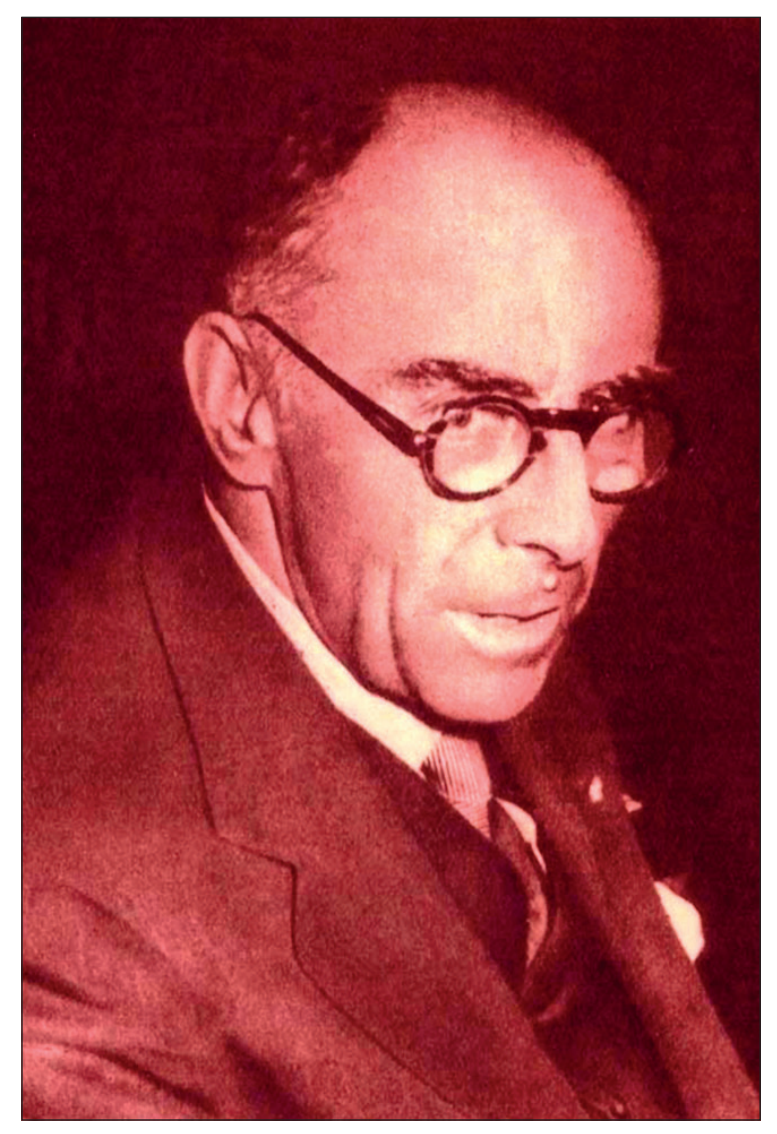

Figura 7

Leopoldo Torres Balbás

Fuente: http:/ / arqarqt.revistas.csic.es/ index.php/arqarqt/article/view/ $218 / 342$

como hizo el ya comentado Vicente Lampérez, con el que Torres Balbás confrontó sus ideas en el VIII Congreso Nacional de Arquitectos de 1919 (Navascués, 1994: 81; Mora, 1999: 55; Ordieres, 1995: 150-151; Martínez et. al., 2008: 293; Muñoz, 2014: 58-59). En él abogó por las enormes posibilidades de los nuevos procedimientos y materiales constructivos, como el cemento armado, que permitía consolidaciones antes impensables; $y$, sobre todo, por la aplicación de materiales modernos siempre y cuando fueran lo suficientemente armoniosos con las partes antiguas del monumento (Ordieres, 1995: 152-153; Muñoz, 2005: 26).

En la comunicación presentada por Torres Balbás a la Conferencia de Atenas de 1931, el arquitecto expuso su intervención en la Alhambra, de la que fue nombrado arquitecto-conservador en 1923, como ejemplo del nuevo espíritu que reinaba en la disciplina restauradora. En ella intentó no caer en falsificaciones, y diferenciar netamente lo nuevo de lo original mediante la utilización de elementos más sencillos, pero ópticamente similares, de tal forma que a cierta distancia produjeran un engaño visual. Únicamente llegó a reestablecer elementos y masas si existía documentación fidedigna sobre cómo realizarlos, dejando los muros desnudos si faltaba decoración (Ordieres, 1995: 155; Martínez et. al., 2008: 293; Muñoz, 2014: 75-77; Mirambell, 2016: 120).

A pesar de la firmeza de sus palabras, tras una primera toma de contacto con la realidad monumental Torres Balbás terminará definiendo su criterio como ecléctico y flexible, según el cual cada edificio debía ser tratado de distinta manera. Todas estas ideas fueron el caldo de cultivo para la promulgación de la Ley de 13 de mayo de 1933, que supuso el triunfo definitivo de las tendencias conservacionistas: restaurar únicamente lo indispensable y dejar siempre reconocibles las adiciones (Navascués, 1987: 295; Ordieres, 1995: 156; Rivera, 2008: 152). Dicha ley fue redactada bajo la influencia de notables seguidores españoles de las doctrinas de Boito y Giovannoni, como el propio Torres Balbás o el arqueólogo e historiador Manuel Gómez-Moreno (Muñoz, 2014: 79).

Precisamente este último, hijo de Manuel Gómez-Moreno González, fue otra de las figuras destacadas de la transición restauradora (Gómez-Moreno, 2016: 21), 
conservacionista y defensor de la mínima intervención, siempre ajustada a su esencia histórica cuando las evidencias lo permitían. Alertó de los peligros que la pura fantasía e invención podían ocasionar en los monumentos, proponiendo intervenir lo menos posible en ellos (Gómez-Morero, 2016: 126-127). Tras la Guerra Civil española, sin embargo, muchos profesionales serían destituidos de sus labores, dando de nuevo un viraje hacia las posturas tradicionalistas y neohistoricistas, lo que supuso un paso atrás en la disciplina (Ordieres, 1995: 157).

\subsection{La actualidad de la restauración arquitectónica española}

Durante el franquismo, la Dirección General de Bellas Artes aún hacía prevalecer criterios restauradores que abogaban por la recuperación del sentido del monumento en sus características originarias (Rivera, 2008: 214; Hernández, 2012: 6). Destaca en este periodo Francisco Prieto Moreno, sucesor de Torres Balbás en la Alhambra tras la Guerra Civil, donde experimentó una clara evolución desde posiciones nada conservacionistas hasta su actuación en el Generalife en los años setenta, mucho más respetuosa y científica (Romero, 2010: 4-6). Fernando Chueca Goitia es otra de las figuras fundamentales, caracterizado por el estudio de la tradición arquitectónica española, lo cual justificó la eliminación de añadidos históricos que según él distorsionaban la unidad espacial y volumétrica de los monumentos (Hernández, 2 012: 6).

La llegada de la democracia trajo consigo la Ley de Patrimonio Histórico Español de 1985, que estableció, aún con cierta ambigüedad, unas líneas de actuación más acordes con la tendencia europea, rompiendo con lo practicado en España hasta el momento (Rivera, 2008: 214-217). A partir de ese momento se produce una mejora significativa en la formación de los profesionales implicados en la restauración arquitectónica, motivada además por el aumento significativo de las intervenciones en edificios históricos de todo el país. En este contexto destaca la «Restauración Objetiva» del arquitecto Antoni González Moreno i Navarro, cuyo proyecto integral incluye amplios y profundos estudios previos, la intervención propiamente dicha y la reflexión sobre el uso futuro del monumento (Rivera, 2008: 218-220).

En los últimos años, la actividad restauradora ha disminuido notablemente debido a que los grandes monumentos españoles ya han sido intervenidos; pero estamos inmersos en un consumismo patrimonial sin precedentes, que parece que ha despertado el interés de las instituciones por conservar la autenticidad de los edificios del pasado. Y precisamente hacia la conservación para evitar restaurar y, cuando no queda más remedio, realizar ésta con las máximas garantías de calidad y respeto, es hacia donde se dirige la disciplina restauradora del siglo XXI, con el perjuicio de estar inmersa en una vorágine económica que enturbia las cosas, todavía por resolver en sus últimas derivaciones la premisa de que nuestros monumentos no pertenecen a las instituciones ni a los políticos, sino a toda la sociedad (Rivera, 2008: 223-224). 


\section{HACIA LA CONSERVACIÓN DE NUESTRO PATRIMONIO}

La restauración historicista se ha convertido en uno de los grandes enemigos de la conservación de nuestro patrimonio, hecho que no deja de ser paradigmático, pues parte de una acción, la restauradora, que tiene precisamente como fin ampliar la vida de aquel mismo patrimonio. Por otra parte, toda restauración historicista implica la pérdida de los testigos de la historia de los edificios en los que se interviene.

A tenor de lo visto hasta ahora, podemos establecer diversos tipos de «falso histórico»:

- «Falso histórico material»: Aun cuando los añadidos reproducen la forma del modelo primigenio, la homogeneización de cronologías constructivas conduce a error en la diferenciación de materiales, a pesar de que la fundamentación histórica de la intervención sea absolutamente rigurosa.

- «Falso histórico formal»: Aun en el caso de que la reconstrucción se realice con materiales originales, si la integración de estos no se hace con rigor, conforme a hipótesis contrastadas, se caerá igualmente en un «falso histórico» debido a que el resultado de la restauración no se ajustará al aspecto originario del edificio. La misma situación puede darse con la utilización de materiales de nueva factura que, incluso bien diferenciados de los antiguos, pueden crear una imagen que nunca existió.

- «Falso histórico total»: Resulta el más grave de todos, pues implica la unión de las dos situaciones anteriores, produciendo no solo un engaño visual entre materiales, sino también un error en la recomposición de la construcción originaria.

Si bien el concepto es reciente, la creación de falsificaciones históricas es casi tan antigua como la realización de obras de arte. Tenemos, por ejemplo, las copias romanas de esculturas griegas, en las que el carácter formal primaba por encima del histórico, pues no importaba que no fueran las realizadas por los autores originales. Sin embargo, para nosotros dichas copias tienen ya otra consideración, pues al valor estético se le suma su capacidad para aludir a la manera de entender el arte que los romanos tenían en su tiempo.

El caso del Panteón de Roma es quizás uno de los primeros «falsos históricos» de la historia, pues no sólo se reconstruye sin que importara el aspecto del edificio anterior, sino que Adriano lo intenta pasar como antiguo, demostrando que para él la valoración material era muy inferior a su carácter simbólico. Y precisamente este aspecto resulta fundamental, pues es obvio que las diversas culturas desarrolladas a lo largo de los tiempos van cambiando su forma de pensar en relación con diversos ámbitos de la vida. La valoración del patrimonio no ha sido menos, y cada pueblo ha atendido de manera diversa a los valores que aglutina, enfatizando unos u otros según el momento. 
De igual manera, en cada periodo histórico se ha dado relevancia a un tipo de patrimonio por encima del resto, según los gustos e inquietudes. Así, durante el neoclasicismo se primaba la recuperación del pasado clásico, mientras el romanticismo prefería rescatar el arte gótico (Mirambell 2016: 49). Sólo en la actualidad somos más conscientes de esta mentalidad, y pretendemos escapar de ella, no tanto conservando todo cuanto nos ha legado el pasado, sino sabiendo recuperar lo más significativo de cada periodo.

No obstante, saber identificar lo más significativo de cada monumento no es tarea sencilla, y de ahí la necesidad de definir qué criterios aplicaremos en la valoración de cada monumento. Conviene para ello conocer el llamado «horizonte de expectativas», a través del cual se puede integrar el carácter histórico y estético de las obras artísticas, además de señalar la variabilidad de su comprensión a lo largo del tiempo (Martínez et al., 2008: 38). El filósofo Hans Robert Jauss estudió el modo y las condiciones en que se efectúa la recepción de un texto, aunque su reflexión puede ser extendida a toda obra de arte. Jauss se preocupa por la consideración histórica de la experiencia estética en el momento de la recepción inicial y sucesiva por parte del público, antes que por la autoría de la obra. Así, propone que el sentido de esta está ligado a una secuencia histórica de interpretaciones parciales y diferentes entre sí, pero no por ello menos válidas (Busso, 2012: 54). El espectador es, de esta manera, el responsable de la atribución de significados y de la formulación de interpretaciones (Borrás, 2004: 272).

Jauss reconoce las enormes influencias de la hermenéutica de Hans-Georg Gadamer (Jauss, 1981: 34; Busso, 2012: 54), ya que para este comprender un texto no es sólo una «comprensión histórica» que reconstruya su génesis, sino que en el proceso de «resurrección del sentido del texto» se encuentran insertas las ideas del intérprete (Gadamer, 1993: 238). Este «horizonte» no supone un punto de vista propio impuesto, sino una opinión o una posibilidad que el lector aporta. Pensar históricamente implica la mediación entre conceptos del pasado y del presente, aportando la propia cultura para pensar lo que la obra es. Entender lo que una obra es, es también entender lo que era en un principio, su evolución futura y las diferentes lecturas que ha tenido (Busso, 2012: 53).

Jauss retoma esta consideración y para él, la relación artista-espectador (autorlector en su caso), también es un proceso de mediación o fusión de dos horizontes: el «horizonte de expectativas de la obra» y el «horizonte de expectativas del receptor». El primero está conformado por las orientaciones que acompañan a la obra y los géneros, forma y temática de obras anteriormente conocidas. El segundo está constituido por la comprensión previa del mundo por parte del lector, que incluye sus expectativas concretas procedentes de sus intereses, deseos, necesidades y experiencias, condicionado además por sus circunstancias sociales (Jauss, 1987; Busso, 2012: 54). 
La interpretación de la arquitectura, en nuestro caso, estará puesta tanto en el edificio como en la sociedad que lo ha realizado. Nuestros monumentos serán completados desde el «horizonte de expectativas» del espectador, ya que su significado y valoración no estarán fijadas, sino que, como dice Jauss, son «entidades relativas» que se actualizan en cada «acto de lectura», abriendo la posibilidad de pensar en la obra desde una dimensión social (Busso, 2012: 54). En toda intervención restauradora debemos reflexionar por tanto sobre cuál es el valor principal en este «horizonte de expectativas», lo que significa estudiar el proceso histórico que ha conformado el monumento y las valoraciones intermedias que han construido la imagen que hoy tenemos sobre él (Martínez et al., 2008: 38).

Pensemos por ejemplo en el caso del santuario japonés de Ise, situado en la en la península de Kii. Este lugar sagrado está formado por un conjunto de 109 templos con formas primitivas, que cada 20 años son destruidos para ser reconstruidos miméticamente en un solar adyacente. Durante la reconstrucción ritual, diversas reliquias son trasladadas en una procesión nocturna desde los antiguos edificios hasta los nuevos. Esta curiosa práctica está relacionada con el animismo sintoísta y se repite desde al menos el siglo VII d. C. Su ciclo ceremonial ha sido visto como una alegoría de la agricultura y la reproducción de especies vegetales a partir de sus semillas. Hoy en día el Santuario de Ise es el único que continúa esta antigua práctica, debido al alto costo de los nuevos materiales empleados y el ceremonial que conlleva su reconstrucción (Falero, 1998: 1-2; Vegas y Mileto, 2003: 14-22; García, 2004: 24).

Pero lo realmente interesante de todo este fenómeno es la manera que tiene de poner en duda los conceptos de restauración, conservación y autenticidad, planteados desde occidente. La atención puesta en su «horizonte de expectativas» es clave para su correcta valoración, pues el patrimonio aquí conservado es realmente el intangible, conformado por el proceso constructivo y las diversas técnicas tradicionales transmitidas de generación en generación. La legislación occidental también incorpora niveles de protección legal para este tipo de patrimonio inmaterial, pero lo realmente curioso es la preeminencia de sus valores simbólicos por encima de una materialidad que en cualquier otro contexto sería conservada íntegramente. Es interesante por otra parte comprobar cómo entre la nómina de monumentos japoneses protegidos no se encuentra Ise, pues entroncaría directamente con la Ley de Patrimonio vigente en el país, que impide la destrucción de monumentos declarados (Vegas y Mileto, 2003: 31-37).

Este ejemplo explica por qué los textos internacionales tienen un carácter puramente recomendatorio. Las cartas en materia de patrimonio son simplemente una hoja de ruta, que de manera general establece los pasos a seguir y los requisitos mínimos de una correcta restauración arquitectónica, pero siempre dejando libertad para que cada nación gestione su propia cultura, según las distintas maneras que tiene su población de interactuar su propio patrimonio. 
Retomando el concepto de «falso histórico», desgraciadamente hoy día seguimos contando con ejemplos que, si bien no parten de la despreocupación de siglos anteriores, sí que caen en los mismos errores. Un caso singular es el del Patronato de la Alhambra: recientemente patentó un mortero con propiedades fluorescentes que permite recomponer las yeserías sin que las modificaciones se perciban a la vista, pero que al exponerlas a la luz reacciona, dejando las partes añadidas al descubierto (Agencia efe, 2015). Esta loable intención entraña una manera de alejar el patrimonio del público de a pie, escondiendo su historia; y es que la diferenciación de materiales en una restauración debe ser tal que cualquiera pueda distinguirla, sin importar formación o nivel cultural. Cualquier otro resultado seguirá suponiendo, a pesar de las buenas intenciones, un «falso histórico» a todas luces.

Algunos autores como el arquitecto Antoni González Moreno-Navarro, han planteado una definición personal para el concepto de falso histórico que, sin duda, puede ser objeto de debate. Según su criterio, en el mundo del patrimonio artístico se considera falso histórico a cualquier intervención que restituya el aspecto original de la obra, por considerar que se inserta en el ciclo cerrado de la creación, substituyendo al propio artista o suplantándolo. Sin embargo, en arquitectura son frecuentes las obras póstumas, terminadas después de la muerte del creador (caso de la Sagrada Familia), lo cual no puede ocurrir en una pintura o una escultura (González, 2007: 5).

De esta manera, sí sería posible insertarse en el ciclo creativo arquitectónico sin cometer falsedad, ya que en arquitectura no existen por lo general ciclos creativos cerrados, sino evoluciones para adaptar las obras a las realidades que las rodean. Por tanto, esta capacidad es una de las características que definen la autenticidad de los monumentos, y completar ese ciclo creativo mediante la restauración no puede constituir tampoco falsedad (González, 2007: 5). Sin embargo, esta visión olvida que precisamente la imperfección es parte de la vida de la arquitectura. Como obra de arte va transformándose a lo largo del tiempo y adquiriendo nuevos significados según la sociedad que la contempla o le da uso.

Los que planteamos no es que no se restauren los monumentos, sino que en ocasiones la laguna, la imperfección o la ruina (hablando en términos ruskinianos) tiene el mismo valor que la absoluta perfección estructural y decorativa, pues es capaz de otorgar al monumento nuevas lecturas y significados que deberán ser respetados sin rectificaciones de ningún tipo, ya que forman parte de la identidad cultural de las sociedades en las que se insertan. A nadie se le ocurriría, por ejemplo, reconstruir las partes ausentes del Coliseo Romano, aun cuando se hiciera con la oportuna diferenciación de materiales añadidos, pues la imagen imperfecta del anfiteatro forma ya parte de la esencia de la propia ciudad. En este tipo de casos nos atrevemos a decir que cualquier modificación generaría falsedad y una pérdida de autenticidad, no tanto del propio edificio, sino de los valores culturales que proyecta, pudiendo ser denominado este caso como «Falso histórico cultural».

Otros ejemplos de falsificaciones pueden ser tratados de manera más relativa. La Carta de Cracovia en su punto cuarto contempla explícitamente la reconstrucción 
de un edificio destruido por un conflicto armado o por desastres naturales, aceptándola siempre y cuando existan motivos sociales o culturales excepcionales (Carta de Cracovia, 2000). Tal fue el caso de Varsovia, donde la memoria colectiva jugó un papel fundamental, pues Hitler expresó personalmente la necesidad de hacerla desaparecer como medio efectivo para destruir la identidad cultural del pueblo polaco; y para conseguir este objetivo no dudó en arrasar su arquitectura. Es por ello que la reconstrucción de Varsovia incorpora además un componente simbólico, pues supone la reacción frente al poder nazi (Figuras 8 y 9) (Gallego, 2007: 25-27).

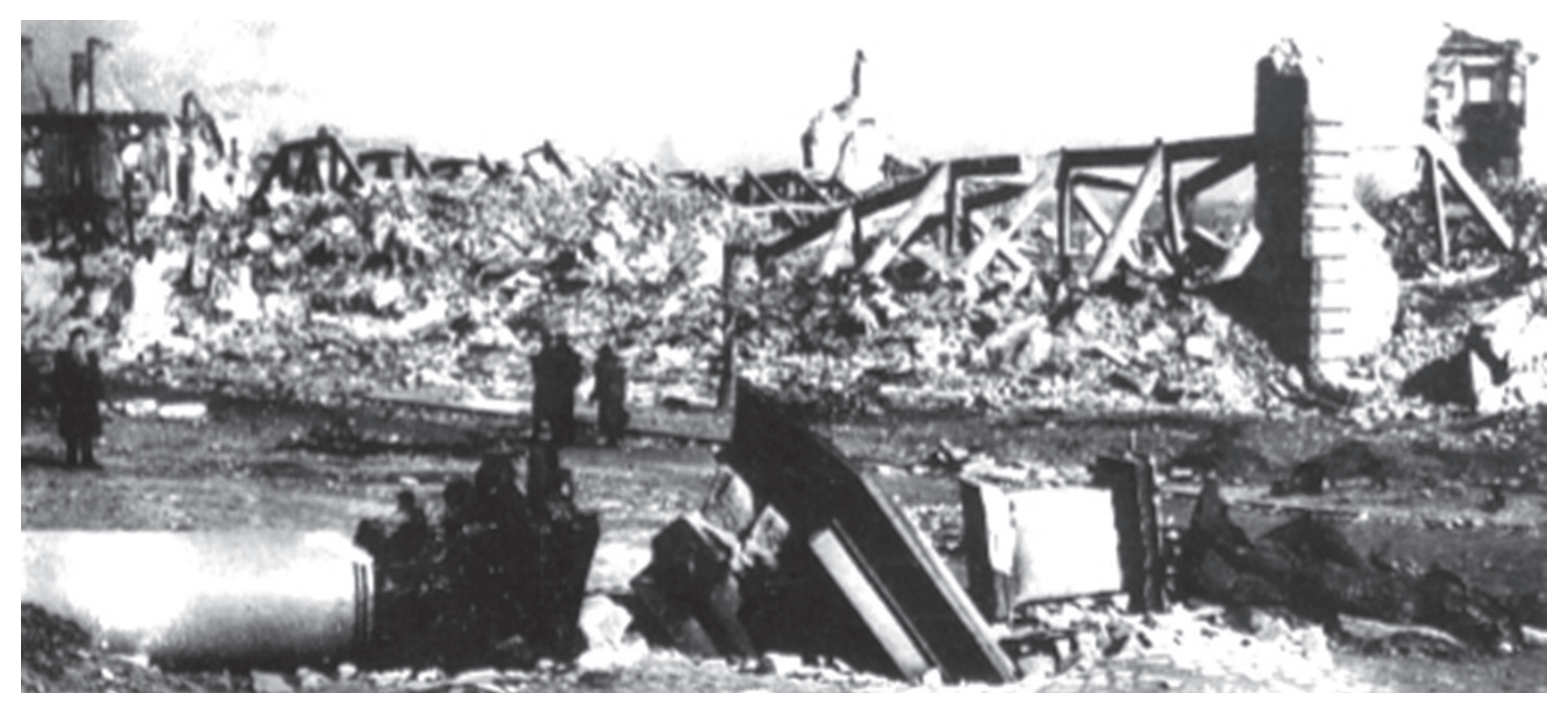

Figura 8

Varsovia. Castillo Real destruido en 1945. GALLEGO ROCA, J. 2007:

«Varsovia, memoria y restauración arquitectónica»

En J. Gallego Varsovia, memoria y restauración arquitectónica. Universidad de Granada. Granada: 39

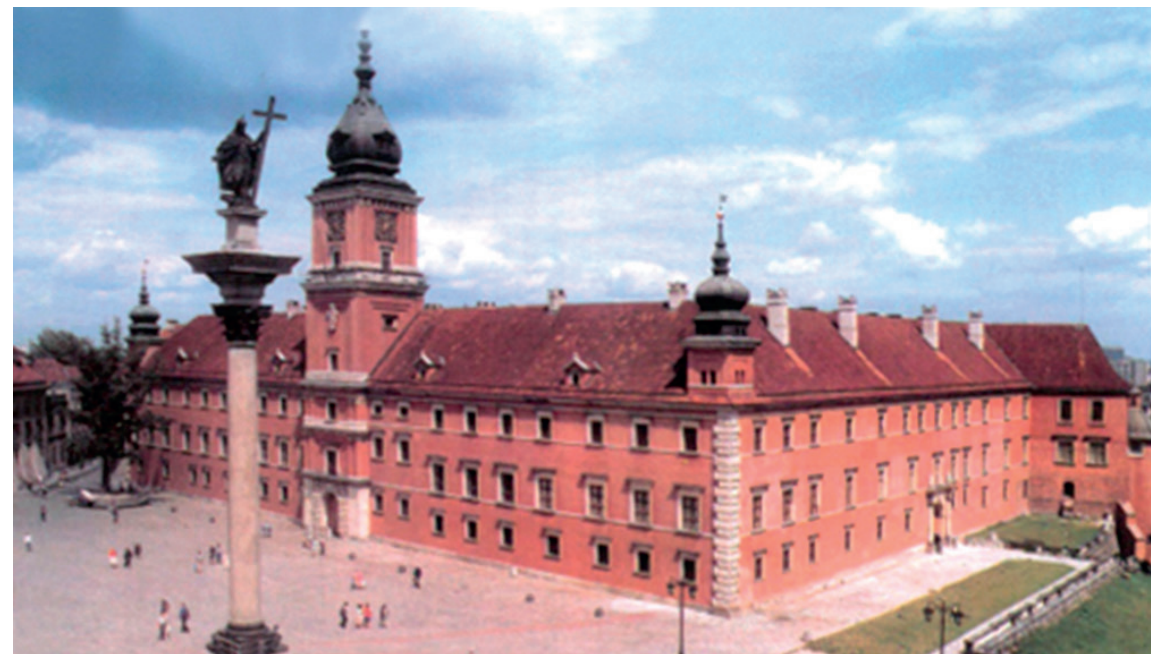

Figura 9

Varsovia. Castillo Real tras su reconstrucción. GALLEGO ROCA, J. 2007: «Varsovia, memoria y restauración arquitectónica»

En J. Gallego Varsovia, memoria y restauración arquitectónica. Universidad de Granada. Granada: 38 
La postura adoptada en Varsovia contrasta con la practicada en otras urbes europeas, como Berlín, donde se dejaron las ruinas tal y como estaban, añadiéndoles, con mayor o menor fortuna, edificios modernos (Gallego, 2007: 24). Y más recientemente destacan los Budas de Bamiyán en Afganistán, dinamitados por los talibanes en 2001, que volvieron en 2015 durante unos días a sus emplazamientos originales gracias a la tecnología de proyección tridimensional (Figura 10) (El Mundo, 2015). La Unesco llegó incluso a decidir que no fueran restaurados, pues el vacío es la verdadera escultura, y su ausencia el mejor recordatorio de la barbarie (García, 2014).

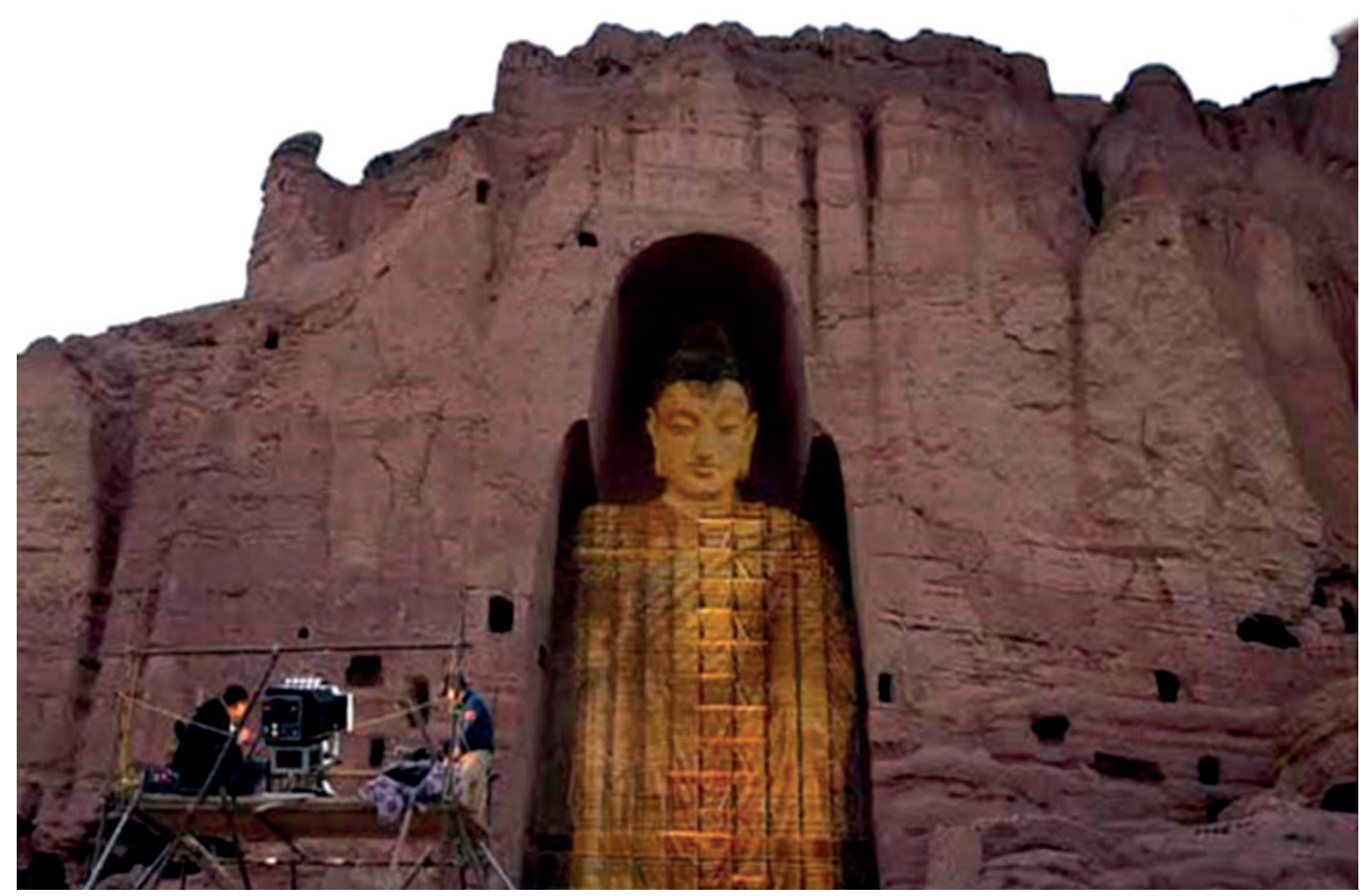

Figura 10

Afganistán. Proyección en 3D del estado originario de uno de los Budas de Bamiyán Sitio web: https: / / www.gettyimages.es/fotos /

amiy $\% \mathrm{C} 3 \% \mathrm{~A} 1 \mathrm{n}$ ?sort=mostpopular\&mediatype $=$ photography\&phrase=bamiy $\% \mathrm{C} 3 \% \mathrm{~A} 1 \mathrm{n}$

España, por su parte, presenta una situación contradictoria, pues a pesar de ser el segundo país del mundo con mayor número de sitios inscritos en la Lista de Patrimonio Mundial, no es hasta hace poco cuando el patrimonio ha ocupado un lugar relevante en las políticas urbanas. La escasez de arquitectos especializados en restauración se traduce en la repetición de metodologías y criterios anacrónicos, al tiempo que la práctica del «fachadismo» mutila el interior de los edificios históricos en beneficio de su exterior. (Vargas, 2016: 104-105). Algunos autores han comparado este tipo de restauraciones con la cosmética, e incluso otros la han bautizado como «sodomía monumental», pues la nueva construcción se inserta en la piel del antiguo edificio, profanándolo y creando una escenografía que contenta únicamente al turista deseoso de una foto para el recuerdo (González, 1991: 14). 
Sirva como ejemplo un caso de la ciudad de Córdoba, en el que la práctica del «fachadismo» se funde con la del falso arquitectónico, creando un auténtico esperpento histórico-artístico: En el n. 23 de la céntrica Avenida del Gran Capitán, se situaba un interesante edificio regionalista de 1924, obra del arquitecto F. Caballero (Daroca et al., 2003: 218). A partir de 2005 fue objeto de estudio para su reforma, proponiéndose en un primer momento la conservación de la fachada del inmueble, protegida por su relevancia histórico-artística. El interior sería de nueva construcción y superaría en altura a la antigua fachada, aunque con las plantas superiores retranqueadas $3,5 \mathrm{~m}$ para no perturbar la contemplación de la misma, proceso habitual en otros edificios históricos de la ciudad (Castelló, 2005: 2-4).

La fachada estuvo varios meses sostenida por andamios antes de ser derribada, sin embargo, los promotores del nuevo proyecto se comprometieron a reproducirla con fidelidad. Esto acabó por generar un falso histórico fusionado con un edificio contemporáneo que asfixia a fachada, pues no se cumplió el retranqueo que en principio se había proyectado para las plantas superiores de nueva construcción. Lo que es seguro es que la ciudad sufrió una grave pérdida, que quiso ser subsanada con una intervención que pretendió respetar la memoria del antiguo edificio, aunque finalmente se creó un pastiche historicista que imposibilita cualquier lectura histórica (Figura 11) (Cabrera, 2012).

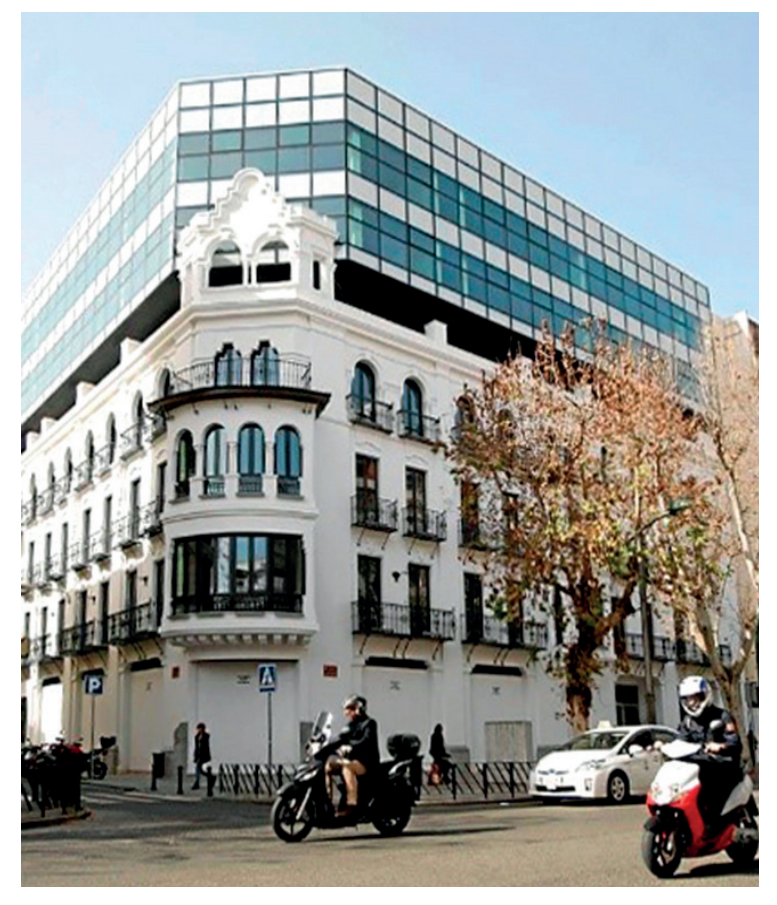

Figura 11

Edificio de la Avenida Gran Capitán n. 23. Córdoba

Sitio web: https: / / www.diariocordoba. $\mathrm{com} /$ noticias/cordobalocal/urbanismodice-uso-hotelero-no-permitido-grancapitan-23_1235585.html
Estas prácticas muestran el excesivo protagonismo por parte de algunos arquitectos, que imprimen un sello demasiado personal en sus intervenciones, desequilibrando la relación antiguo-nuevo (Vargas, 2016: 105). El ejemplo quizás más célebre es el Teatro de Sagunto, Bien de Interés Cultural (BIC) y Monumento Histórico Artístico Nacional desde 1896. $\mathrm{Su}$ restauración, llevada a cabo entre 1990 y 1994, está considerada como una de las más polémicas y de peor resultado del panorama nacional. También supone el perfecto ejemplo de cómo en ocasiones los intereses políticos y económicos prevalecen sobre la protección de edificios protegidos, provocando auténticos «disparates» patrimoniales (Parrado, 2019).

Su rehabilitación fue encargada a los arquitectos Giorgio Grassi y Manuel Portaceli, siendo muy polémica desde el principio por abordar la construcción de un teatro nuevo sobre la destrucción del 
teatro romano original (Figura 12). Aun cuando el Tribunal Superior de Justicia de la Comunidad Valenciana la consideró ilegal y se ordenó la demolición de gradas y escenario, la sentencia fue recurrida por la Generalitat Valenciana y el Ayuntamiento de Sagunto, alegando imposibilidad de ejecución por el coste que suponía devolver el monumento a su estado anterior; lo cual nos recuerda que, en muchas ocasiones, el criterio de reversibilidad que debe estar presente en toda intervención no es verdaderamente respetado (Parrado, 2019). Y es que, la libertad que se le da a las administraciones municipales en cuestiones patrimoniales puede generar este tipo de situaciones. Además, el coste económico de estos proyectos hace difícil dar marcha atrás si se cometen excesos, sobre todo cuando se trata de pequeños municipios que han hecho una importante apuesta por la conservación de su patrimonio, aunque los resultados puedan ser cuestionables.

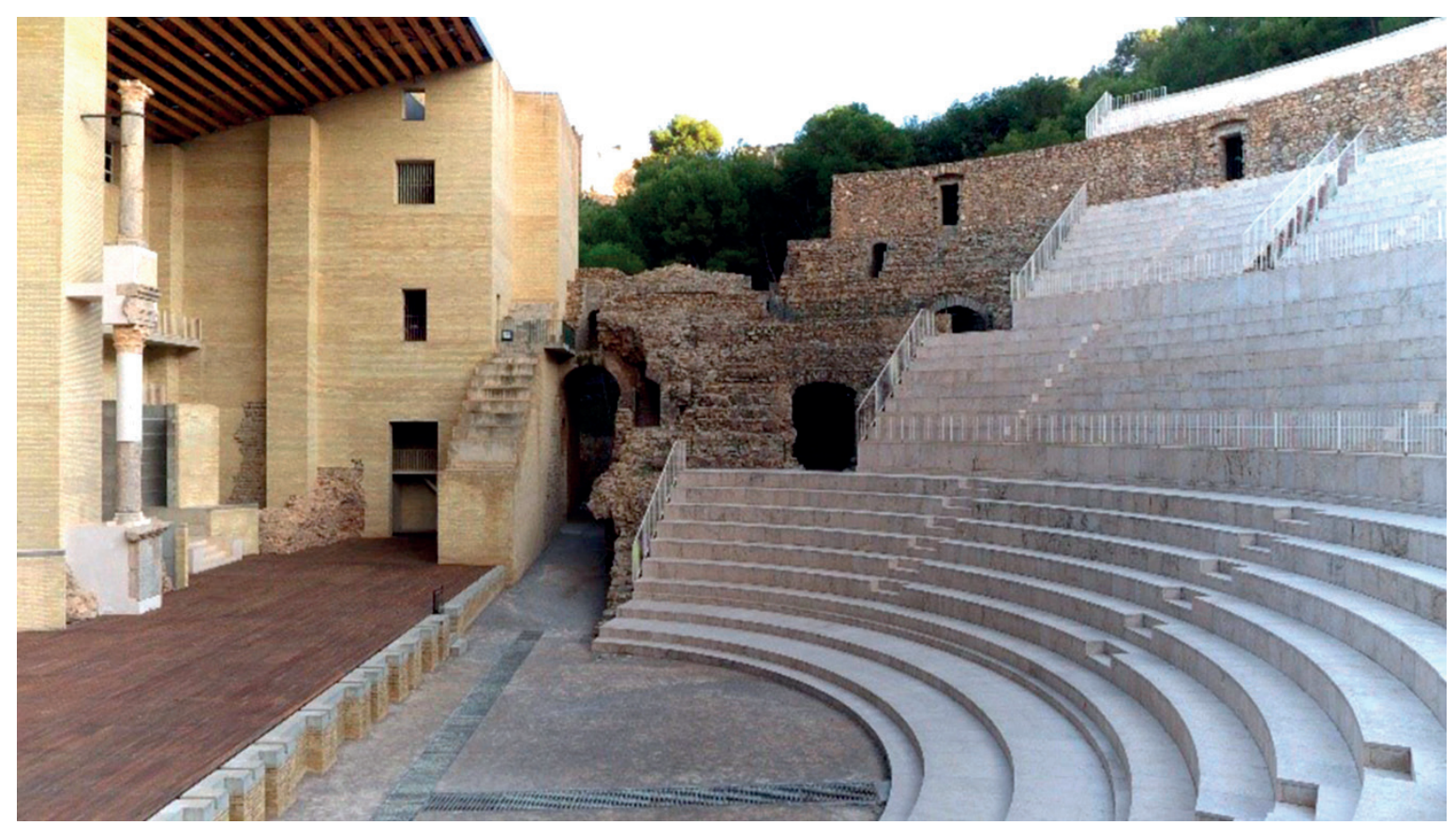

Figura 12

Teatro Romano de Sagunto

Sitio web: https://ca.wikipedia.org/wiki/Fitxer:Teatro_romano_de_Sagunto.jpg 


\section{CONCLUSIONES}

El aparente consenso en el panorama restaurador que muestran en la actualidad las instituciones internacionales es fruto de años de teorización, debate y práctica arquitectónica. La secuencia que hemos planteado en periodos no supone una cronología completamente cerrada, pues se han repetido en distintas épocas los mismos criterios imperantes en el pasado. En el caso de España, hemos mostrado de manera más explícita algunas actuaciones concretas en monumentos nacionales que han servido, más que los textos teóricos, como auténticos campos de pruebas y fuentes de conocimiento para ulteriores intervenciones. Cabe recordar la importancia histórica de la Catedral de León, donde trabajaron y/o se formaron algunos de los autores de las intervenciones monumentales más destacadas de la historia nacional.

Este repaso histórico nos ha permitido comprender que el fenómeno de los historicismos en restauración arquitectónica no es exclusivo de un único periodo. Bien es cierto que hasta la etapa estilística el «falso histórico» no era considerado como una práctica negativa, sino como un intento loable de recuperar la imagen original de los monumentos, pero con la llegada del siglo XX y de la Carta de Atenas los principios restauradores a favor de la conservación terminan por desterrar metodologías benévolas con la restauración historicista.

Hoy nos encontramos con un arma de doble filo, pues el plano teórico aparece gobernado por las aportaciones de textos internacionales como la Carta de Cracovia, que ha supuesto una síntesis de años de reflexión patrimonial; sin embargo, su carácter simplemente recomendatorio hace que en la práctica se observen notables diferencias de criterio. Aun cuando este hecho pueda tentarnos a proponer una mayor obligatoriedad de los marcos normativos internacionales, no sería lógico homogeneizar la enorme diversidad de criterios restauradores adoptados a lo largo y ancho del mundo, pues cada pueblo tiene una manera distinta de valorar su patrimonio, poniendo mayor énfasis en aspectos que pueden no son tenidos en cuenta por estas cartas de alcance internacional.

Por otro lado, la diferenciación entre materiales antiguos y nuevos como manera de eludir el falso histórico implica un grave problema, y es que en ocasiones la distinción resulta tan evidente que los añadidos restan protagonismo a la obra primigenia. De ahí que toda intervención deba contar con la presencia de un arqueólogo y/o historiador del arte, capaz de complementar con sus conocimientos el trabajo del arquitecto, garantizando así el respeto histórico-artístico hacia el monumento. 


\section{REFERENCIAS BIBLIOGRÁFICAS}

AGENCIA EFE (2015): «La Alhambra patenta un mortero para que en las restauraciones se perciban los arreglos». EFE [En línea], 3 de octubre.

Disponible en https://www.efe.com/efe/espana/cultura/la-alhambra-patenta-unmortero-para-que-en-las-restauraciones-se-perciban-los-arreglos/10005-2728972 [Consulta: 18/08/2018].

AMITRANO. R. F. (1985): «Evolución y desarrollo de los criterios de restauración de la antigüedad al panorama actual», Revista de Arqueología, n. 47, 20-33.

ARRECHEA, J. I. (1998): «La Arquitectura como reencuentro: Viollet-le-Duc». En: Restauración arquitectónica II. Ed. por Represa, I. Valladolid: Universidad de Valladolid, 85-106.

BELLINI, A. (1998): «La restauración, el conocimiento histórico y la moderna presencia del pasado». En: Restauración arquitectónica II. Ed. por Represa, I. Valladolid: Universidad de Valladolid, 9-32.

BORRÁS, L. (2004): «De la estética de la recepción a la estética de la interactividad. Notas para una hermenéutica de la lectura hipertextual», Actas del X Congreso de la Asociación Española de Semiótica. Logroño, 272-287.

BUSSO, M. P. (2012): «Un recorrido sobre el autor: su problematización en Gadamer, Jauss y Eco», Revista latinoamericana de comunicación. Chasqui, n. 118, 52-56.

CABRERA, J. (2012): «Gran Capitán, 23». El Día de Córdoba [En línea], 22 de junio. Disponible en https://www.eldiadecordoba.es/opinion/articulos/Gran-Capitan23_0_599640738. html [Consulta: 02/06/2019].

CALAMA, J. M. y GRACIANI, A. (1998): La restauración decimonónica en España. Sevilla: Universidad de Sevilla.

CAPITEL, A. (1998): «La restauración y la actitud ante la Historia de la Disciplina». En: Restauración arquitectónica II. Ed. por Represa, I. Valladolid: Universidad de Valladolid, 33-44.

CARTA DE ATENAS (1931): «Conferencia Internacional de Arquitectos y Técnicos de Monumentos Históricos», Carta de Atenas para la restauración de monumentos históricos. [En línea] Disponible en http://www.icomoscr.org/doc/teoria/VARIOS.1931.carta.atenas. restauracion.monumentos.historicos.pdf [Consulta: 22/08/2018].

CARTA DE CRACOVIA (2000): «Conferencia Internacional sobre Conservación», Carta de Cracovia para la conservación y restauración del patrimonio construido. [En línea] Disponible en https://ipce.mecd.gob.es/dam/jcr:b3b6503d-cf75-4cb0-adaf-226740ebd654/2000 -carta-cracovia.pdf [Consulta: 22/08/2018].

CARTA DE VENECIA (1964): «Congreso Internacional de Arquitectos y Técnicos de Monumentos Históricos», Carta de Venecia sobre la conservación y la restauración de monumentos y sitios. [En línea] Disponible en https://www.icomos.org/charters/venice_sp.pdf [Consulta: 22/08/2018]. 
CASTELLÓ, R. (2005): Estudio de detalle del edificio sito en Avenida del Gran Capitán n. 23 de Córdoba. Córdoba, Colegio Oficial de Arquitectos de Córdoba.

DAROCA, F.; YLLESCAS, M.; DE LE FUENTE, F. (2003): Guía de Arquitectura de Córdoba. Junta de Andalucía, Consejería de Obras Públicas y Transportes.

DE LACHENAL, L. (1995): Spolia. Uso e reimpiegodell'anticodal III al XIV secolo. Milano: Longanesi\&C.

EL MUNDO (2015): «Los budas destruidos por los talibán hace 14 años reviven en 3D». El Mundo [En línea], 15 de junio. Disponible en http://www.elmundo.es/cultura/ 2015/06/15/557f001aca4741607b8b45a6.html [Consulta: 23/08/2018].

FALERO, A. (1998): «El shinto de Ise», Conferencia pronunciada en la Universidad Politécnica de Valencia. Universidad de Valencia.

FERNÁNDEZ, R. (1997): «Notas para una introducción a la teoría y práctica restauradora». En: Teoría e Historia de la Restauración. Ed. por Aymat, C. Madrid: Munilla-Lería, 47-99.

GADAMER, H. G. (1993): Verdad y Método. Salamanca, Ediciones Sígueme.

GALLEGO, J. (2007): «Varsovia, memoria y restauración arquitectónica». En: Varsovia, memoria y restauración arquitectónica. Ed. por Gallego, J. Granada: Universidad de Granada, $17-42$.

GALLEGO, P. L. (1992): «Viollet le Duc: La restauración arquitectónica y el racionalismo arqueológico fin de siglo». En: Restauración arquitectónica. Ed. por Ángel, L. Valladolid: Universidad de Valladolid, 29-50.

GALLEGO, P. L. (1998): «Vicente Lampérez y la cultura fin de siglo: arqueología, estilo, restauración». En: Restauración arquitectónica II. Ed. por Represa, I.Valladolid: Universidad de Valladolid, 107-140.

GARCÍA, J. E. (1998): Arte español de la Ilustración y del siglo XIX: En torno a la imagen del pasado. Madrid: Encuentro.

GARCÍA, F. (2004): «Los espacios sagrados de Japón: Santuarios sintoístas y templos budistas». Laboratorio de arte, n. 17, 21-38.

GARCÍA, V. (2014): Budas de Bamiyán, una restauración que «bordea lo criminal». El País [En línea], 7 de febrero. Disponible en http://blogs.elpais.com/con-arte-y-sonante/2014/02/ budas-de-bamiyan-una-restauracion-que-bordea-lo-criminal.html [Consulta: 23/08/2018].

GÓMEZ-MORENO, J. (2016): Manuel Gómez-Moreno Martínez (1870-1970). Granada: Atrio.

GONZÁLEZ, A. (1991): «La restauración de monumentos a las puertas del siglo XXI», Informes de la Construcción 43, 5-20.

GONZÁLEZ, A. (1996): «Falso histórico o falso arquitectónico, cuestión de identidad», Loggia, n. 1, 16-23.

GONZÁLEZ, A. (2007): «Restaurar es reconstruir. A propósito del nuevo monasterio de Sant Llorenç de Guardiola de Berguedà (Barcelona)», E-rph dic., 2-19. 
GONZÁLEZ-VARAS, I. (2000) Conservación de Bienes Culturales. Teoría, historia, principios y normas ( $2^{\circ}$ ed.). Madrid: Cátedra.

HERNÁNDEZ, A. (2012): «Fernando Chueca Goitia y el arte mudéjar aragonés: arquitectura, historia y restauración. La intervención en la iglesia de San Félix de Torralba de Ribota» (1953-1972), E-rph (revista electrónica de patrimonio histórico) [En línea] n. 10, 1-6. Disponible en http://www.revistadepatrimonio.es/revistas/numero10/intervencion/ estudios2/articulo.php [Consulta: 15/08/2018].

JAUSS, H. R. (1981): «Estética de la comunicación y comunicación literaria», Punto de Vista, n. $12,34-40$.

JAUSS, H. R. (1987): Estética de la recepción. Madrid: Arcos.

MACARRÓN, A. M. (2013): Historia de la conservación y la restauración. Desde la Antigüedad hasta el siglo XX. (3ºd.). Madrid: Tecnos.

MARTÍNEZ, E. (1999): «La restauración consciente en el siglo XIX. Recuperación de arquitecturas y ciudades medievales». En: Teoría en historia de la rehabilitación. Ed. por Aymat, C. Madrid: Munilla-Lería, 15-30.

MARTÍNEZ, M. J., SÁNCHEZ-MESA, d., SÁNCHEZ-MESA, L. (2008): Historia y Teoría de la Conservación y Restauración Artística ( $3^{\circ}$ ed.). Madrid: Anaya.

MÉNDEZ, L. (2012): El Ayuntamiento de Sevilla. Sevilla: ICAS.

MIRAMBELL, M. (2016): Criterios y teorías de la conservación y la restauración del patrimonio artístico a lo largo de la historia. Madrid: Jas.

MIRRI, M. B. (2009): Per una storiadella tutela del patrimonio culturale. Viterbo: SetteCittà.

MORA, S., (1999): «La restauración arquitectónica en España (1840-1936): Teoría y Práctica». En: Teoría en historia de la rehabilitación. Ed. por Aymat, C. Madrid: Munilla-Lería, 47-78.

MUÑOZ, A. (2005): La vida y la obra de Leopoldo Torres Balbás. Sevilla: Junta de Andalucía.

MUÑOZ, A. (2014): «Leopoldo Torres Balbás y la teoría de la conservación y la restauración del patrimonio», Papeles del partal. n. 6, 55-82.

NAVASCUÉS, P. (1987): «La restauración monumental como proceso histórico: el caso español, 1800-1950», Curso de mecánica y tecnología de los edificios antiguos. COAM, 285-329.

NAVASCUÉS, P. (1994): «La restauración de monumentos en España: aproximación bibliográfica (1954-1994)», VII Jornadas de arte, 22 y 25 noviembre. Madrid, 77-88.

ORDIERES, I. (1995): Historia de la restauración monumental en España (1835-1936). Madrid: Ministerio de Cultura.

PARDO, M. A. (2006): Un siglo de restauración monumental en los conjuntos históricos declarados de la provincia de Badajoz: 1900-2000. Tesis doctoral no publicada. Cáceres: Universidad de Extremadura.

PAREJO, J. (2015): «Los secretos de las Casas Consistoriales», Diario de Sevilla [En línea], 29 de diciembre. Disponible en https://www.diariodesevilla.es/sevilla/secretosCasas-Consistoriales_0_985101909.html [Consulta: 10/08/2018]. 
PARRADO, D. (2019): «Siete ejemplos de conservación de patrimonio polémicos, contados por los expertos», El País [En línea], 31 de marzo. Disponible en https://elpais.com/el pais/2019/03/29/icon_design/1553873489_312054.html [Consulta: 02/06/2019].

PEÑA, A. (2010): Estudio de la decoración arquitectónica romana y análisis del reaprovechamiento de material en la Mezquita Aljama de Córdoba. Córdoba: Universidad de Córdoba.

RIVERA, J. (1997): «Restauración arquitectónica desde los orígenes hasta nuestros días. Conceptos, teoría e historia». En: Teoría e Historia de la Restauración. Ed. por Aymat, C. Madrid: Munilla-Lería, 103-169.

RIVERA, J. (2008): De varia restauratione: Teoría e historia de la restauración arquitectónica. Madrid: Abada Editores.

ROMERO, A. (2010): «Apuntes y reflexiones en torno a la obra restauradora del arquitecto Francisco Prieto-Moreno y Pardo», E-rph (revista electrónica de patrimonio histórico) [En línea], n. 17, 1-8. Disponible en http://www.revistadepatrimonio.es/revistas/numero7/ intervencion/estudios/articulo.php [Consulta: 15/08/2018].

RUSKIN, J. (1956): Las siete lámparas de la arquitectura (2ºd.). Buenos Aires: El Ateneo.

VARGAS, C. (2016): Criterios de restauración, intervención y revitalización del patrimonio industrial. La fábrica de gas de San Paolo en Roma. Tesis doctoral no publicada. Madrid: Universidad Politécnica de Madrid.

VEGAS, F., MILETO, C. (2002): «El espacio, el silencio y la sugestión del pasado. El Santuario de Ise en Japón», Loggia n. 14-15, 14-41. 
